NBER WORKING PAPER SERIES

\title{
THE CREDIT CHANNEL IN MIDDLE INCOME COUNTRIES
}

\author{
Aaron Tornell \\ Frank Westermann \\ Working Paper 9355 \\ http://www.nber.org/papers/w9355 \\ NATIONAL BUREAU OF ECONOMIC RESEARCH \\ 1050 Massachusetts Avenue \\ Cambridge, MA 02138 \\ November 2002
}

We thank Debajyoti Chakrabarty, Antonio Garcia, Michael Hutchison, Mark Muendler, Martin Schneider and seminar participants at CIDE, IMF, Konstanz, Munich and UC Santa Cruz for helpful discussions. The views expressed herein are those of the authors and not necessarily those of the National Bureau of Economic Research.

(C) 2002 by Aaron Tornell and Frank Westermann. All rights reserved. Short sections of text, not to exceed two paragraphs, may be quoted without explicit permission provided that full credit, including (C) notice, is given to the source. 
The Credit Channel in Middle Income Countries

Aaron Tornell and Frank Westermann

NBER Working Paper No. 9355

November 2002

JEL No. E32, F32, G15, O16

\section{ABSTRACT}

Credit market conditions play a key role in propagating shocks in middle income countries (MICs). In particular, shocks to the spread between domestic and international interest rates have a strong effect on GDP, and an even stronger effect on domestic credit. This strong credit channel is associated with a sharp sectorial asymmetry: the output of the bank-dependent nontradables $(\mathrm{N})$ sector reacts more strongly than tradables $(\mathrm{T})$ output. This asymmetry, in turn, is associated with a strong reaction of the real exchange rate --the relative price between $\mathrm{N}$ and $\mathrm{T}$ goods.

We present a model that reconciles these facts and leads to a well specified estimation framework. From the equilibrium we derive structural VARs that allow us to identify shocks to credit market conditions and trace their effects on the economy. We estimate these structural VARs for a group of MICs and find evidence of a strong credit channel. We argue that at the heart of the MIC credit channel are a deep asymmetry in financing opportunities across $\mathrm{N}$ and $\mathrm{T}$ sectors, and a severe currency mismatch. This makes movements in the real exchange rate the driving element in the amplification of shocks. Finally, we show that the model's key assumptions are consistent with evidence gleaned from both firm level and aggregate data.

Aaron Tornell

Department of Economics

UCLA, 405 Hilgard Avenue

Bunche 8283

Los Angeles, CA 90095

and NBER

tornell@econ.ucla.edu
Frank Westermann

CESifo

University of Munich and ifo Institute

Schackstr. 4

80539 Munich

Germany

Westermann@cesifo.de 


\section{Introduction}

Credit market conditions are playing an increasingly important role in middle income countries (MICs). With inflation under control in many MICs, it is now swings in credit, investment and asset prices that affect MICs the most. In this paper we present a framework to analyze both theoretically and empirically how credit market shocks are propagated and amplified in MICs.

The credit channel is strong in MICs. The spread between lending and foreign interest rates has a strong effect on GDP and an even stronger effect on credit. ${ }^{1}$

The strength of the credit channel in MICs is associated with a sharp asymmetry between the tradeables $(\mathrm{T})$ sector and the more bank-dependent nontradables (N) sector. Each of the sectors reacts differently to shocks, with real exchange rate fluctuations playing a key role in amplification. Furthermore, credit varies strongly with the N-to-T output ratio and movements in credit are strongly correlated with those of the real exchange rate -the relative price between $\mathrm{N}$ and $\mathrm{T}$ goods. In contrast, GDP and credit growth are not closely correlated, and the credit-to-GDP ratio experiences large swings.

These comovements and asymmetric sectorial responses are not observed in high income countries. They appear to be the same across MICs, in spite of different exchange rate regimes, and arise both in the course of boom-bust cycles as well as at higher frequencies. The patterns thus raise several questions. Is the monetary transmission mechanism in MICs the same as in high income countries? What is an appropriate estimation framework to characterize economic fluctuations in MICs? What are the implications for the design of economic policy?

In this paper we argue that credit market imperfections prevalent in MICs are the key to explaining the stylized facts, and thus to addressing the questions we have raised. We document both the stylized facts and the imperfections that can explain them. We then present a model with a financial accelerator in which real exchange rate fluctuations play a key role in amplifying the effects of shocks and generating a strong credit channel.

The equilibrium imposes unambiguous contemporaneous linkages among key macroeconomic variables and allows us to derive structural VARs. Estimating these VARs using quarterly data for a group of MICs, we find evidence for a

\footnotetext{
${ }^{1}$ In the US the effect of the spread on output has been considered an indicator that monetary shocks affect the economy through a credit channel, which is distinct from the traditional money channel. See for instance, Bernanke, Gertler, and Gilchrist (2000), Friedman and Kuttner (1992), and Stock and Watson (1989).
} 
strong credit channel, for asymmetric sectorial responses and for balance sheet effects.

In MICs there is a pronounced asymmetry in financing opportunities across the T- and N-sectors: T-sector firms tend to be large and have access to world capital markets; $\mathrm{N}$-sector firms are smaller on average and are bank-dependent. ${ }^{2}$ In addition, a substantial amount of $\mathrm{N}$-sector debt is dollar denominated, while the income streams that service those debts are in domestic currency. As a result, the degree of currency mismatch is significant. ${ }^{3}$ Finally, creditors are covered, either explicitly or implicitly, by systemic guarantees. It is expected that if a critical mass of debtors risks insolvency, policies to ensure that creditors will be repaid will be implemented

When there is a positive shock to the lending rate, $\mathrm{N}$-sector agents can borrow less at each level of net worth. The resulting reduction in demand for N-goods generates a fall in the price of $\mathrm{N}$ goods. In the presence of currency mismatch this real depreciation reduces the net worth of $\mathrm{N}$-sector agents. The reduction in net worth, in turn, further tightens borrowing constraints, reinforcing the drop in demand for N-goods, and so on. T-sector agents, on the other hand, are not bank-dependent and so T-output is not negatively affected by the shock. Thus, there is a decline in both the N-to-T output ratio and the credit-to-GDP ratio, as is observed in the data. ${ }^{4}$ In sum, the N-sector exhibits a balance sheet effect that acts as a financial accelerator to amplify the effect of shocks on the economy. ${ }^{5}$

Of course, in order for a model to provide a satisfactory rationalization for the amplification mechanism, the existence of currency mismatch and borrowing constraints cannot be taken as exogenously given. Furthermore, the model should allow us to derive a set of equilibrium equations that are suitable for estimation across MICs. To achieve both objectives we will consider a model of a monetary

\footnotetext{
${ }^{2}$ In MICs T-sector firms have easy access to external finance because they can either pledge export receivables as collateral, or can get guarantees from closely linked firms.

${ }^{3}$ Even when the banks' balance sheets are equilibrated, banks face a de facto currency mismatch because they lend primarily to the $\mathrm{N}$-sector. Thus, they face insolvency risk.

${ }^{4}$ There are two views as to what mechanism underlies the credit channel: credit falls because either firms' ability to borrow falls or banks capacity to lend declines. We do not distinguish between these two views in this paper.

${ }^{5}$ The sectorial asymmetry in financing opportunities prevalent in MICs is closely related to the small vs. large dichotomy made in the US literature. In the US researchers have found an excess sensitivity of small banks and firms (e.g., Gertler and Gilchrist (1994) and Kashyap and Stein (2000)). The difference in MICs is the special role of the N-Sector's excess sensitivity in giving rise to real exchange rate fluctuations.
} 
economy with credit market imperfections that is subject to demand shocks.

The stable equilibrium of such an economy has two attractive features. First, the paths of the key variables are independent of the nominal exchange rate regime, which is important because of a wide variation across MICs in this regard. Second, an empirical characterization of economic fluctuations follows directly from the equilibrium: (a) it determines which variables to include in the empirical specification; and (b) it provides us with identifying restrictions to characterize causal links among the variables, and to structurally identify the effects of shocks.

With structural VARs in hand, we estimate the strength of the credit channel using quarterly data for several MICs. We find that both GDP and credit exhibit strongly negative responses to shocks to the interest rate spread (Figure 4.1), indicating that there is a strong credit channel in MICs. We also find that in response to an increase in the spread there is a decline in the N-to-T output ratio and a real depreciation (Figures 4.2 and 4.3). There is a striking similarity between these impulse response functions and the simulated responses in our model economy, which are shown in Figure 4.5.

The VARs implied by our model are similar to those in the literature in that they link an interest rate spread with a measure of output. However, there are several differences related to the variables we include, and to the way we identify our structural VARs. We include variables that measure asymmetric sectorial patterns: the N-to-T output ratio and the real exchange rate. Second, we include the difference between the domestic lending rate and the world interest rate, which is the relevant spread in the presence of currency mismatch and a sectorial asymmetry in financing opportunities.

With regards to identification, the ordering of our VAR follows directly from the model's equilibrium. As the model implies, the spread is not allowed to respond to GDP surprises within a quarter. In MICs the monetary authority has little leeway to influence the spread through standard open market operations. Instead, changes in the spread reflect mainly changes in the anticipated generosity of the guarantees. The expected generosity, in turn, depends on the ability and the willingness of the government to cover the guarantees. Clearly, these factors cannot be changed at short notice in response to a quarterly GDP surprise.

The paper is structured as follows. In Section 2 we characterize the comovements between key macro variables across MICs, and we present an intuitive explanation of the amplification mechanism. In Section 3 we present a model that formalizes the mechanism and establishes causal links among the comovements. In Section 4 we use the restrictions implied by the model to estimate structural 
VARs. In Section 5 we provide evidence for the credit market imperfections that are key to our argument. In Section 6 we present some extensions. Finally, in Sections 7 and 8 we present a review of the literature and the conclusions, respectively.

\section{Comovements and an Amplification Mechanism}

Here we give a first pass at the comovements among key macroeconomic variables in MICs, and give an overview of a mechanism that amplifies shocks in MICs and produces these comovements.

We characterize the comovements by means of panel regressions and event windows over the period 1980-1999 on a set of MICs where, in addition to banks, the stock market is a viable source of finance. ${ }^{6}$ In the panel regressions, we allow for random and fixed effects. ${ }^{7}$ The partial correlations cannot, of course, be interpreted as causal relations. However, they indicate what variables theoretical models should emphasize.

The first regression in Table 2.1 shows that an increase in credit is associated with (i) a decline in the interest rate spread, (ii) an increase in the ratio of $\mathrm{N}$ to-T output, and (iii) a real appreciation. It is remarkable that these partial correlations are significant at the $1 \%$ level. Correlation (i) suggests the existence of a credit channel. Correlation (ii) is consistent with the fact that the N-sector is more credit-constrained than the T-sector. Correlation (iii) is consistent with the existence of a balance sheet effect. ${ }^{8}$

Among components of GDP, what is surprising is the dog that didn't bark: consumption and net exports do not move with credit growth. In contrast, investment and the fiscal deficit vary strongly with credit. Regressions 2 and 3 show that all parameters, except those on consumption and net exports, are significant at the 5\% level. We find similar results using fixed effects estimation (Table 2.2). After dropping insignificant variables, all remaining variables are significant at the

\footnotetext{
${ }^{6}$ This set consists of 39 countries and is defined in Tornell and Westermann (2002). See Appendix for details.

${ }^{7}$ All variables are in first differences in order to avoid the issues associated with nonstationarity.

${ }^{8}$ The MICs we examine have experienced crises from time to time during the sample period. We are not limiting ourselves to analyzing the events surrounding crises, and the comovements of Tables 2.1 and 2.2 are not conditional on the occurrence of crises.
} 
Table 2.1: Random Effects Model

Dependent Variable: Real Credit Growth

\begin{tabular}{|c|c|c|c|c|}
\hline \multirow{3}{*}{$1 /$ Real exchange rate } & (1) & (2) & (3) & (4) \\
\hline & $0.370 * * *$ & $0.356 * * *$ & $0.212 *$ & $0.216^{* *}$ \\
\hline & $(0.074)$ & $(0.089)$ & $(0.112)$ & $(0.106)$ \\
\hline \multirow[t]{2}{*}{$\mathrm{N} / \mathrm{T}$ output ratio } & $0.294 * * *$ & $0.387 * * *$ & $0.241 *$ & $0.290 * *$ \\
\hline & (0.109) & $(0.127)$ & $(0.139)$ & $(0.137)$ \\
\hline \multirow[t]{2}{*}{ Interest rate spread } & & $-0.002 * *$ & $-0.071 * * *$ & $-0.063 * * *$ \\
\hline & & $(0.001)$ & $(0.021)$ & $(0.020)$ \\
\hline \multirow[t]{2}{*}{ Investment } & & & $0.306 * * *$ & $0.219 * * *$ \\
\hline & & & $(0.107)$ & $(0.078)$ \\
\hline \multirow[t]{2}{*}{ Consumption } & & & -0.228 & \\
\hline & & & $(0.263)$ & \\
\hline \multirow[t]{2}{*}{ Deficit } & & & $0.614 * *$ & $0.591 * *$ \\
\hline & & & $(0.249)$ & $(0.259)$ \\
\hline \multirow[t]{2}{*}{ Net exports } & & & 0.000 & \\
\hline & & & $(0.001)$ & \\
\hline Adj. $R^{2}$ & 0.211 & 0.180 & 0.363 & 0.376 \\
\hline \# countries & 30 & 26 & 25 & 25 \\
\hline
\end{tabular}

Note:. The table reports the regression results from a model with random effects. Standard errors are reported in parentheses; * indicates significance at the 10 percent level, $* *$ indicates significance at the 5 percent level and $* * *$ indicates significance at the 1 percent level. 
Table 2.2: Fixed Effects Model

Dependent Variable: Real Credit Growth

\begin{tabular}{|c|c|c|c|c|}
\hline & (1) & (2) & (3) & (4) \\
\hline $1 /$ Real exchange rate & $\begin{array}{c}0.398 * * * \\
(0.081)\end{array}$ & $\begin{array}{c}0.374 * * * \\
(0.053)\end{array}$ & $\begin{array}{c}0.258^{* *} \\
(0.119)\end{array}$ & $\begin{array}{c}0.234 * * \\
(0.113)\end{array}$ \\
\hline N/T output ratio & $\begin{array}{c}0.273 * * * \\
(0.081)\end{array}$ & $\begin{array}{c}0.295^{* * *} * \\
(0.040)\end{array}$ & $\begin{array}{c}0.198 \\
(0.151)\end{array}$ & $\begin{array}{c}0.283^{*} \\
(0.146)\end{array}$ \\
\hline Interest rate spread & & $\begin{array}{l}-0.002 \\
(0.001)\end{array}$ & $\begin{array}{c}-0.073 * * * \\
(0.022)\end{array}$ & $\begin{array}{c}-0.064 * * * \\
(0.021)\end{array}$ \\
\hline Investment & & & $\begin{array}{c}0.324 * * * \\
(0.112)\end{array}$ & $\begin{array}{c}0.203 * * \\
(0.083)\end{array}$ \\
\hline Consumption & & & $\begin{array}{l}-0.390 \\
(0.282)\end{array}$ & \\
\hline Deficit & & & $\begin{array}{c}0.617 * * \\
(0.295)\end{array}$ & $\begin{array}{c}0.583 * * \\
(0.294)\end{array}$ \\
\hline Net exports & & & $\begin{array}{c}0.000 \\
(0.001)\end{array}$ & \\
\hline Adj. $\mathrm{R}^{2}$ & 0.155 & 0.143 & 0.317 & 0.376 \\
\hline \# countries & 30 & 26 & 25 & 25 \\
\hline
\end{tabular}

Note:. GLS regression results from a model with fixed effects. Standard errors are reported in parentheses; * indicates significance at the 10 percent level, ** indicates significance at the 5 percent level and $* * *$ indicates significance at the 1 percent level. 
$5 \%$ level and have the same sign as in the random effects model. ${ }^{9}$

We do not focus on crises in this paper. Nevertheless, it is important to emphasize that around times of crisis, macroeconomic variables display similar comovements to those shown in Tables 2.1 and 2.2. Figure 2.1 shows that prior to a crisis there is a real appreciation and a lending boom during which credit grows unusually fast. In the aftermath of a crisis there is typically a short-lived recession and a protracted credit crunch that mainly affects the N-sector. In fact, N-production declines relative to the output of the T-sector and the credit-toGDP ratio continues to fall for several years after the crisis. Investment is the component of GDP that exhibits by far the largest (and statistically significant) deviations from tranquil times, while consumption deviations are very mild and insignificant. ${ }^{10}$

These stylized facts suggest that investment, rather than consumption, should play a key role in the amplification mechanism. Furthermore, they indicate that a model of the credit channel in MICs should generate an equilibrium path along which credit varies negatively with the spread and the real exchange rate, and positively with the N-to-T output ratio.

\footnotetext{
${ }^{9} \mathrm{~A}$ further issue is the apparent presence of serial correlation in the error terms as reflected in the low value of the Durbin Watson test statistics. We will deal with this issue in section 4 .

${ }^{10}$ Figure 2.1 is taken from Tornell and Westerman (2002). See that paper for details.
} 


\section{Figure 2.1: The Boom-Bust Cycle}

a) Real Appreciation

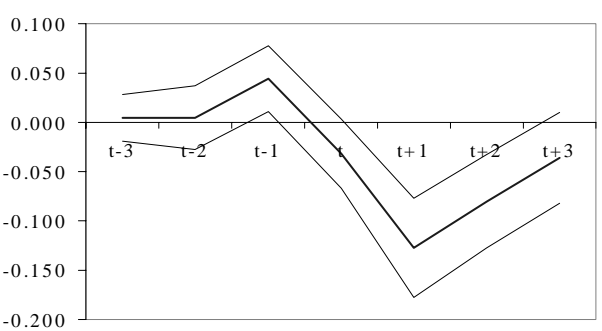

c) N-to-T Output Ratio

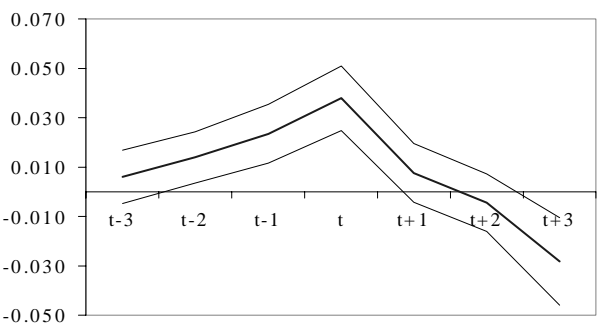

e) Investment/GDP

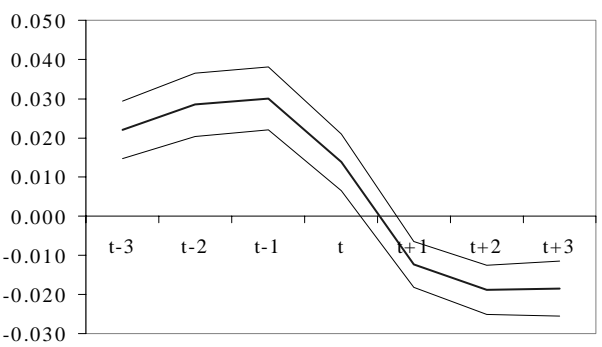

b) Credit/GDP

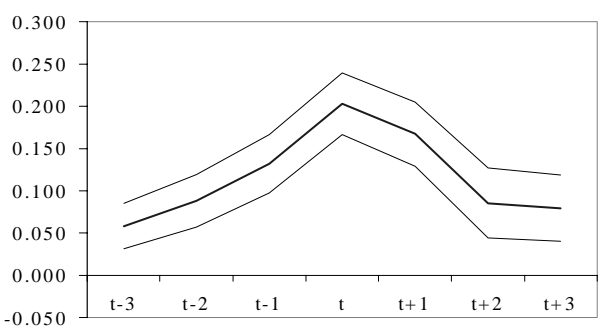

d) Interest Rate Spread

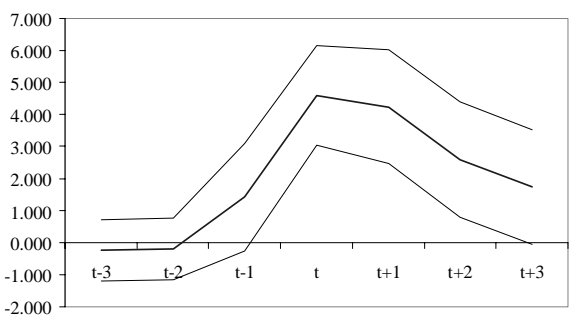

f) Consumption/GDP

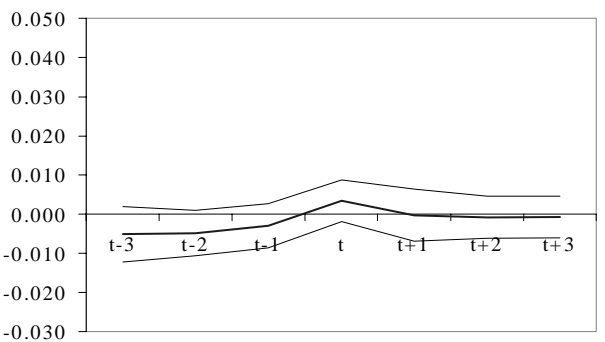

Note: The figures show the average behavior of the respective variable, across 39 countries around twin currency and banking crises during the period 1980-1999. Index $t$ in the figures refers to the year during which a twin crisis takes place. The figures are the visual representations of the point estimates and standard errors from regressions in which the respective variable in the graph is the dependent variable, regressed on time dummies preceding and following a crisis. The panel data estimations include fixed effects and use a GLS estimator. The heavy line represents the average deviation relative to tranquil times. The thin lines represent the $95 \%$ confidence interval. 


\section{Overview of the Model}

We consider a simple dynamic general equilibrium model of an economy with two sectors: a tradables sector $(\mathrm{T})$ and a nontradables sector $(\mathrm{N})$. T-sector agents have access to perfect capital markets, but N-sector agents face agency problems. Thus, their credit is constrained by their net worth. Using this framework we construct an equilibrium in which borrowers find it optimal to denominate their debt in foreign currency.

Along the equilibrium path the amplification mechanism works as follows. An increase in the domestic lending rate leads to higher debt service obligations and thus implies that firms can now borrow less at each level of net worth. Lower borrowing results in lower investment. This direct effect is amplified if there is currency mismatch and part of N-sector's demand comes from the N-sector itself. In this case, the fall in demand for N-goods, leads to a real depreciation. Since Nsector agents have dollar debt on the books, while their revenues are denominated in the local currency, there is a fall in N-sector's profits and net worth. A vicious circle ensues as lower net worth leads to even lower investment, which leads to a lower demand for $\mathrm{N}$-goods and a steeper real depreciation, which leads to lower net worth and so on.

T-sector agents have access to international capital markets and can more easily substitute away from domestic borrowing. Thus, their decisions are mostly affected by the world interest rate, not by the domestic lending rate. Therefore, an increase in the spread between these two interest rates is associated with a real depreciation, a decline in the N-to-T output ratio, and a fall in credit. Furthermore, the sectorial asymmetry implies that the decline in GDP growth is milder than that of credit. This explains the persistent swings in the credit-to-GDP ratio observed in the data.

One question remains. Why is there a currency mismatch? The answer relies on the existence of systemic guarantees. It is a stylized fact, which we document in this paper, that governments insure creditors against systemic crises. That is, if a critical mass of borrowers is on the brink of bankruptcy, the government will implement policies to ensure that creditors get repaid (at least in part) and thus avoid an economic meltdown. These policies may come in the form of an easing of monetary policy, the maintenance of an exchange rate peg, or the handing out of checks. ${ }^{11}$

\footnotetext{
${ }^{11}$ Systemic guarantees, broadly defined, are not limited to MICs but are in fact prevalent the world over. For instance, consider the announcement made by the Bank of Japan in September
} 
If the expected generosity of the guarantee is large enough, borrowers will find it optimal to take on insolvency risk. By doing so they can cash in on the subsidy implicit in the guarantee, as the government will pay the debt obligation in case of insolvency. If the real exchange rate is expected to be sufficiently variable, currency mismatch is a prime vehicle for $\mathrm{N}$-sector agents to take on insolvency risk. By denominating their debt in foreign currency, $\mathrm{N}$-sector agents will pay dirt cheap interest rates as someone else will repay creditors in case of a sharp real depreciation.

Since the real exchange rate is endogenous, a self-reinforcing mechanism arises. Agents choose dollar debt only if there is enough expected real exchange rate variability to make it optimal to do so. The required variability, in turn, arises only if there is currency mismatch at the aggregate level, and demand risk is translated into insolvency risk along the equilibrium path.

This is as far as simple intuition can bring us. Since relative prices are determined in general equilibrium we need the aid of the model to guide our intuition as to when demand risk generates enough expected real exchange rate variability. Some restrictions will have to be imposed on the parameters to ensure that the right balance exists between the opposing forces at work in this economy. The question then becomes one of whether these parameter restrictions generate an equilibrium path that exhibits the comovements typical of MICs. Is an increase in the spread associated with a real depreciation, as well as with higher output and credit growth? Does a lending boom coincide with a real appreciation and an increasing N-to-T ratio? We show in Proposition 3.2 that there is indeed a combination of parameters that ensures the existence of a 'risky symmetric equilibrium' (RSE) that exhibits currency mismatch and these comovements.

In Section 4 we derive structural VARs from Proposition 3.2 by shocking the expected generosity of the guarantee $(g)$ in an RSE. We then bring the model to the data and investigate whether there is a strong credit channel and whether there is a balance sheet effect.

2002 that it will commit several billion dollars to purchase stocks owned by troubled banks. This is an instance of how monetary policy can act as a systemic guarantee. Still another example is the many banks that became overexposed to the telecoms and technology sectors. When these sectors suffered a fall in their ability to raise funds, and risked bankruptcy, a low interest rate policy acted as a systemic guarantee. 


\section{Model}

We consider a simple dynamic general equilibrium model of an economy with a T-sector and an N-sector. The model embeds the credit market game of Schneider and Tornell (2000), henceforth ST, into a monetary economy that is hit by exogenous demand shocks. The bold lines in Figure 3.1 illustrate the channels that the model will emphasize. The dashed lines refer to channels that are not necessary for the argument we wish to make, but which could be added without affecting the amplifying mechanism. Key is that the demand for N-goods has an upward sloping component. As we shall see, the fact that the N-sector demands its own goods for investment and that currency mismatch arises in equilibrium is sufficient to produce this upward sloping demand. ${ }^{12}$

Figure 3.1:

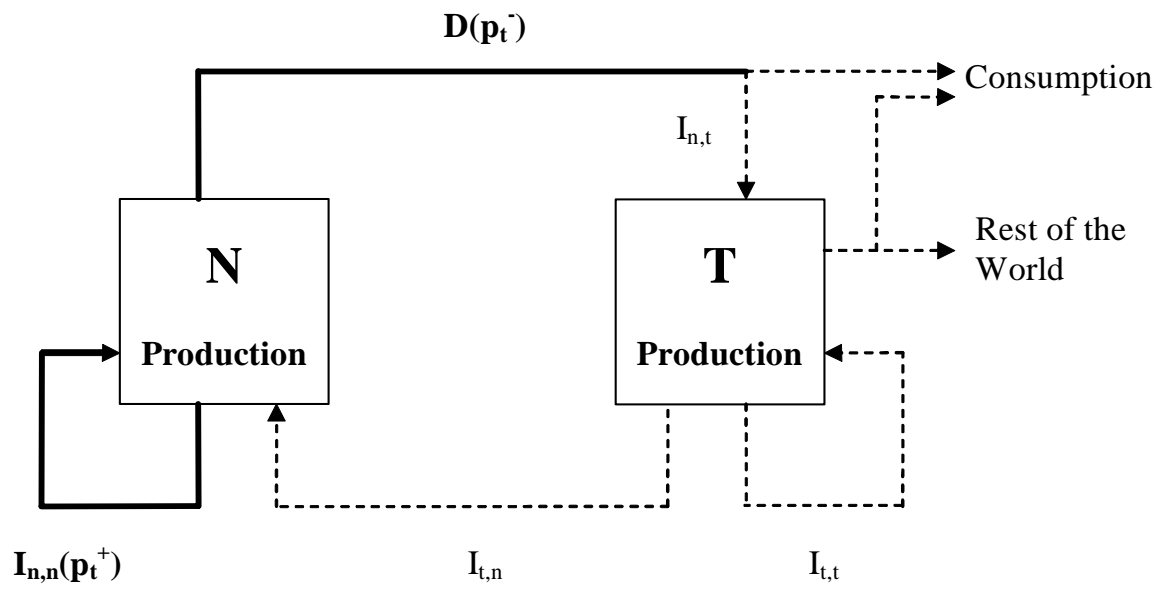

\footnotetext{
${ }^{12}$ Since the economy is small and open, the destination of T-goods is not important for our argument.
} 


\subsection{Setup}

As previously mentioned, there are $\mathrm{N}$ and $\mathrm{T}$ goods in our model economy. $\mathrm{N}$ goods can only be purchased with local currency (pesos), while T-goods can only be purchased with foreign currency (dollars). Using pesos as the

numeraire, we will denote the nominal exchange rate by $e_{t}$, the price of $\mathrm{N}$-goods by $p_{t}^{n}$, and the price of T-goods by $p_{t}^{t r}$.

Real exchange rate variations in MICs reflect mainly changes in the relative price of $\mathrm{N}$ and T goods. ${ }^{13}$ To capture this fact we assume that purchasing parity holds and that the dollar price of foreign T-goods is fixed, so that $p_{t}^{t r}=e_{t}$. It follows that the inverse of the real exchange rate is

$$
p_{t}=\frac{p_{t}^{n}}{e_{t}}
$$

\section{$N$-Sector Firms}

There is a continuum, of measure one, of N-producing firms run by overlapping generations of managers. An N-sector manager is allowed to enter into one-period debt contracts denominated in either dollars or pesos. In a dollar contract he gets $b_{t}$ dollars at $t$ and promises to pay $\left(1+\rho_{t}\right) b_{t}$ dollars at $t+1$. In a peso contract he gets $b_{t}^{p s}$ pesos and promises to repay $\left(1+\rho_{t}^{p s}\right) p_{t+1}^{n} b_{t}^{p s}$ pesos. Lenders are competitive risk neutral agents whose cost of funds (in dollar terms) equals the world interest rate $r$.

In order for the amplification mechanism described in the introduction to exist, it is necessary that part of the demand for $\mathrm{N}$-goods comes from the $\mathrm{N}$-sector itself. Thus, we assume that $\mathrm{N}$-sector firms produce $\mathrm{N}$-goods using only $\mathrm{N}$-goods as inputs $\left(I_{t}\right)$ according to a linear production technology

$$
q_{t+1}^{n}=\theta I_{t}
$$

The representative young manager begins period $t$ with a net worth equal to $e_{t} w_{t}$ pesos. Thus, his budget constraint is

$$
p_{t}^{n} I_{t}=e_{t} w_{t}+e_{t} b_{t}+b_{t}^{p s}
$$

\footnotetext{
${ }^{13}$ Betts and Kehoe (2001) find that in a set of 52 countries over the period 1980-2000 real exchange rate variations reflect mainly changes in the relative price of $\mathrm{N}$ and $\mathrm{T}$ goods, not movements in the international relative prices of T-goods. Among some developed countries the latter channel is more important (Engel (1999)).
} 
At time $t+1$ the firm's net worth in terms of pesos is

$$
\pi_{t+1}^{p s}:=p_{t+1}^{n} q_{t+1}^{n}-p_{t+1}^{n}\left[1+\rho_{t}^{p s}\right] b_{t}^{p s}-e_{t+1}\left[1+\rho_{t}\right] b_{t}
$$

\section{Enforceability Problem}

In order to capture the fact that N-sector firms are financially constrained, we assume that a manager will be able to divert borrowed funds at $t+1$ if at $t$ he incurs a cost proportional to his investable funds: $h\left[e_{t} w_{t}+e_{t} b_{t}+b_{t}^{p s}\right]$. The parameter $h$ can be interpreted as a measure of the severity of the contract enforceability problem, with a low $h$ representing lax contract enforcement.

Lenders only finance plans that do not lead to diversion. Since the goal of every manager is to maximize next period's expected profits net of diversion costs, the plans that are financed are those where the expected debt repayment is no greater than the diversion cost.

\section{Systemic Guarantees}

There are several ways of modeling systemic guarantees. We choose to model them as a commitment made by the government at time $t$ to repay lenders, at $t+1$, a fraction $g_{t} \in[\underline{g}, 1]$ of the outstanding debts of all defaulting borrowers if more than $50 \%$ of borrowers become insolvent at $t+1$ (i.e., $\pi_{t+1}<0$ ). The guarantee applies to both peso and dollar debt. Thus, if a crisis were to occur at $t+1$, the bailout payment would equal

$$
G_{t+1}=g_{t}\left[e_{t+1} b_{t}\left[1+\rho_{t}\right]+p_{t+1}^{n}\left[1+\rho_{t}^{p s}\right] b_{t}^{p s}\right]
$$

The value of $g_{t}$ is common knowledge as of time $t$. The bailout payment is financed by an international organization. ${ }^{14}$

\section{Consumption and T-production}

Consumption and T-output are not central to the model and will be treated as exogenous. ${ }^{15}$ The supply of T-goods $q_{t}^{t r}$ will play no role in the determination of equilibrium and we will refer to it only when we define GDP in Section 4.

\footnotetext{
${ }^{14}$ The bailout could instead be financed by a tax on the T-sector.

${ }^{15}$ Demand (3.6) and a T-sector supply function of the form $q_{t+1}^{t r}=\varepsilon_{t} q_{t}^{t r}$ can be derived from an optimizing setup in which T-sector agents have access to perfect capital markets. For example, ST consider a setup where competitive T-producing firms produce T-goods using labor (supplied by consumers) and T-capital as inputs, and where consumers derive utility from consumption of both $\mathrm{T}$ and N-goods.
} 
We assume that the demand for N-goods that originates outside the N-sector is decreasing in the relative price of N-goods $\left(p_{t}\right)$ and it experiences shocks.

$$
D_{t}\left(p_{t}\right)=\frac{d_{t}}{p_{t}}, \quad d_{t}= \begin{cases}d & \text { with probability } \alpha \\ 0 & \text { with probability } 1-\alpha\end{cases}
$$

There are two states of nature: in the good state there is a high demand for Ngoods $\left(d_{t}=d\right)$, while in the bad state there is a low demand $\left(d_{t}=0\right)$. Expected demand variability will be the source of expected real exchange rate variability, the presence of which will be necessary for dollar debt to be optimal. As we shall see, $\alpha$ must be large, but less than one, in order for an equilibrium to exist. ${ }^{16}$

\section{The Money Market}

To introduce a demand for pesos we assume that $\mathrm{N}$-goods can be purchased only with pesos, while T-goods can be purchased only with dollars. Furthermore, we assume that the central bank's assets consist only of foreign exchange reserves $R_{t}$. Thus, the peso demand and supply satisfy

$$
M_{t}^{d} \geq p_{t}^{n}\left[I_{t}+D_{t}\right] \quad \text { and } \quad M_{t}^{s}=e_{t} R_{t}
$$

\section{Sequence of Actions}

Every new manager starts period $t$ with net worth of $e_{t} w_{t}$ pesos, and chooses a plan $\left(I_{t}, b_{t}, b_{t}^{p s}, \rho_{t}, \rho_{t}^{p s}\right)$ that satisfies the budget constraint and the no diversion condition. During $t+1$ each (now old) manager sells the output of his firm. If the firm is solvent $\left(\pi_{t+1}>0\right)$, he repays debt. He then pays out a fraction $c$ of profits to himself and passes on the remainder to the next manager. In contrast, if the firm is insolvent $\left(\pi_{t+1} \leq 0\right)$ the old manager gets nothing, while the new manager receives an 'aid payment' of $\underline{w}_{t}$ dollars to jump start the firm.

Lenders receive the debt repayments of solvent firms. In the case that more than half of the firms default, a bailout is granted. Lenders then receive a fraction $g_{t}$ of the outstanding debt. Lastly, in period 0 there is both a cohort of initial incumbent managers who have an amount $q_{0}$ of nontradables to sell and a cohort of new managers who have an endowment of $w_{0}$ dollars. It follows that for $t \geq 1$

\footnotetext{
${ }^{16}$ Note that it is not necessary that demand be zero in the bad state. Any $\underline{d}<d$ will do. Note also that we consider demand shocks instead of supply shocks (i.e., shocks to $\theta$ ) because the latter would imply a real appreciation in the bad state. This is counterfactual.
} 
net worth evolves according to

$$
e_{t} w_{t}=\left\{\begin{array}{lr}
{[1-c] \pi_{t}^{p s}} & \text { if } \pi_{t}^{p s}>0 \\
e_{t} \underline{w}_{t} & \text { otherwise }
\end{array}\right.
$$

\section{Equilibrium Concept}

In a 'symmetric equilibrium' during every period (i) lenders break even; (ii) the representative young manager chooses a plan to maximize expected profits, subject to the budget constraint and the no diversion condition, taking as given current and future prices, as well as the generosity of the guarantee; and (iii) the non-tradables market as well as the money market clear

$$
\frac{d_{t}}{p_{t}}+I_{t}=q_{t}^{n}, \quad M_{t}^{s}=M_{t}^{d}
$$

Two comments are in order. First, the equilibrium determines only the real exchange rate $1 / p_{t}=e_{t} / p_{t}^{n}$, and not the levels of $p_{t}^{n}$ and $e_{t}$ separately. The levels of these variables depend on the specifics of the exchange rate regime. Second, exogenous shocks to the demand for N-goods are the only source of insolvency risk. Demand variability, in turn, generates real exchange rate variability through (3.9). Since $d_{t}$ may equal either $d$ or $0, p_{t+1}$ might equal $\bar{p}_{t+1}$ with probability $\alpha$ or $\underline{p}_{t+1}$ with probability $1-\alpha$. We would like to emphasize that assuming demand risk is not the same as assuming insolvency risk. The fact that $d_{t}=0$ does not imply that $\mathrm{N}$-firms will go bust unless a majority of $\mathrm{N}$-firms have a significant amount of dollar debt on the books.

\subsection{Currency Mismatch}

There are two types of symmetric equilibria: risky and safe. In the former there is currency mismatch and insolvency risk, while in the latter there is none. We derive risky symmetric equilibria (RSE) in two steps. In this subsection we characterize equilibria within a given period, taking prices as given and assuming that there is 'sufficient expected real exchange rate variability'

$$
\frac{\alpha \theta \bar{p}_{t+1}}{p_{t}} \geq 1+r>\frac{h}{\alpha} \geq \frac{\theta \underline{p}_{t+1}}{p_{t}}
$$


We then ask in subsection 3.3 whether there is a self-validating equilibrium process $\left\{p_{t}, \bar{p}_{t+1}, \underline{p}_{t+1}\right\}_{t=0}^{\infty}$ that satisfies $(3.10) .{ }^{17}$

Consider first the problem of an individual manager who takes current prices $\left(p_{t}\right)$ and expected future prices $\left(\bar{p}_{t+1}, \underline{p}_{t+1}\right)$ as given, and who expects that a bailout $\left(g_{t}\right)$ will be granted next period in the bad state, but not in the good state. A manager must decide whether to borrow, and in what currency to denominate any debt he does take on. He may denominate the debt all in dollars or all in pesos, or use some combination of the two. We consider the implications of each of these choices in turn and then show that both borrowing constraints and currency mismatch arise in equilibrium provided (3.10) holds.

Consider the case in which all debt is denominated in dollars. In this case, the firm will go bust in the bad state (i.e., $\pi\left(\underline{p}_{t+1}\right) \leq 0$ ) provided there is insolvency risk -i.e., the third inequality in (3.10) holds. However, since there are systemic guarantees, lenders will get repaid a proportion $g_{t}$ of what the firm promises. Thus, if the manager issues only dollar debt, the interest rate $\left(\rho_{t}\right)$ that allows lenders to break-even satisfies

$$
\left[1+\rho_{t}\right]\left[\alpha+(1-\alpha) g_{t}\right]=1+r
$$

It follows that the manager will choose to borrow if and only if expected returns are high enough so as to make the production of N-goods profitable -i.e., the first inequality in (3.10) holds. Lenders will lend up to an amount that makes the expected debt repayment $\alpha\left[1+\rho_{t}\right] b_{t}$ equal to the diversion cost

$$
\alpha\left[1+\rho_{t}\right] b_{t} \leq h\left[w_{t}+b_{t}\right]
$$

Notice that this condition becomes a borrowing constraint for all $g_{t} \in[0,1]$ only if the second inequality in (3.10) holds. If this were not the case and $h$, the measure of the enforceability problem, were greater than $\alpha[1+r]$, it would always be cheaper to repay debt rather than to divert.

Combining borrowing constraint (3.12) with the budget constraint $p_{t}^{n} I_{t}=$ $e_{t}\left[w_{t}+b_{t}\right]$ we obtain

$$
I_{t}=\mu\left(g_{t}\right) \frac{w_{t}}{p_{t}}, \quad \quad \mu\left(g_{t}\right):=\frac{1}{1-h\left[1+\frac{1-\alpha}{\alpha} g_{t}\right][1+r]^{-1}}
$$

\footnotetext{
${ }^{17}$ If $\frac{\alpha \theta \bar{p}_{t+1}}{p_{t}}<1+r$ or $\frac{h}{\alpha} \geq 1+r$, borrowing constraints would not arise in equilibrium. If $\frac{h}{\alpha}<\frac{\theta \underline{p} t+1}{p_{t}}$, there would be no currency mismatch.
} 
This equation shows that investment of a credit constrained firm depends not only on the rate of return, but also on its net worth. With our linear structure, the rate of return enters only through the positive NPV condition.

Consider now the case in which all debt is denominated in pesos. Clearly, in this case the firm will never go bust. Since lenders must break even, the interest rate that the manager would have to offer satisfies $\left[1+\rho_{t}^{p s}\right] E_{t}\left(\frac{p_{t+1}^{p}}{e_{t+1}}\right)=\frac{1+r}{e_{t}}$. Since (3.10) holds, the manager will borrow up to an amount that makes the credit constraint binding: $\left(1+\rho_{t}^{p s}\right) b_{t}^{p s} p_{t+1}^{n} \leq h\left(e_{t} w_{t}+b_{t}^{p s}\right)$. The budget constraint $p_{t}^{n} I_{t}=e_{t} w_{t}+b_{t}^{p s}$ then implies that investment is given by $I_{t}^{p s}=\mu^{p s} \frac{w_{t}}{p_{t}}$, where $\mu^{p s}:=\frac{1}{1-h[1+r]^{-1}}$.

Will the borrowing manager choose dollar debt or peso debt? The incentives to choose risky dollar debt derive from the fact that if a majority of $\mathrm{N}$-firms become insolvent, the government will pay part of the debt obligations of those borrowers that go bust. Since lenders must break even, choosing dollar debt over peso debt reduces the cost of capital from $1+r$ to $[1+r]\left[1+\frac{1-\alpha}{\alpha} g_{t}\right]^{-1}$. Lower borrowing costs ease the borrowing constraint and investment is higher relative to a plan financed with peso debt $\left(I_{t}>I_{t}^{p s}\right)$. But a risky plan has a downside in that it entails a probability $1-\alpha$ of insolvency. To see which plan is preferred we compute the expected payoffs in dollar terms

$$
\begin{aligned}
\Pi_{t+1}^{d l r}\left(g_{t}\right) & =\left[\alpha \frac{\theta \bar{p}_{t+1}}{p_{t}}-h\right] \mu\left(g_{t}\right) \cdot w_{t} \\
\Pi_{t+1}^{p s} & =\left[\alpha \frac{\theta \bar{p}_{t+1}}{p_{t}}+(1-\alpha) \frac{\theta \underline{p}_{t+1}}{p_{t}}-h\right] \mu^{s} \cdot w_{t}
\end{aligned}
$$

Thus, the manager will chooses dollar debt over peso debt if and only if $\Pi_{t+1}^{d l r} \geq$ $\Pi_{t+1}^{p s}$. If crises are rare events $(\alpha \rightarrow 1)$ and the expected guarantee $g_{t}$ is generous enough, the benefits of issuing dollar debt outweigh the bankruptcy costs. In contrast, in the absence of guarantees (i.e., $g_{t}=0$ or $\alpha=1$ ), the two benefits associated with dollar debt disappear. Thus, the borrowing manager will refrain from financing his plan with risky dollar debt. ${ }^{18}$

In order to determine the equilibrium at a point in time recall that guarantees

\footnotetext{
${ }^{18}$ Consider plans in which debt is denominated partly in pesos and partly in dollars. It can be verified that if such a plan does not lead to insolvency in any state, it generates an expected payoff of $\Pi_{t+1}^{p s}$. In contrast, if such a plan leads to insolvency in the bad state, it is dominated by a plan in which all debt is denominated in dollars.
} 
apply only to systemic meltdowns. If nobody expects a bailout, everybody hedges, and a crisis -and hence a bailout- cannot occur. In other words, a safe symmetric equilibrium always exists. This is independent of whether there is enough real exchange rate variability or not. However, in a world with guarantees there is also an RSE. Indeed, suppose that a manager believes that all other managers will borrow in dollars. He will conclude that a bailout will occur in the bad state. Thus, he will take on real exchange rate risk and go bankrupt in the bad state, along with all other managers, triggering a bailout. For further reference we summarize the results of this subsection in the following proposition.

Proposition 3.1 (Currency Mismatch). Dollar debt arises in equilibrium if and only if there is sufficient expected real exchange rate variability (i.e., (3.10) holds) and the expected guarantee $\left([1-\alpha] g_{t}\right)$ is sufficiently large so that $\Pi_{t+1}^{d l r}\left(g_{t}\right) \geq$ $\Pi_{t+1}^{p s}$. Credit is determined by net worth:

$$
b_{t}=\left[\mu\left(g_{t}\right)-1\right] w_{t}
$$

The real exchange rates associated with the good and bad states are

$$
\frac{1}{\bar{p}_{t}}=\frac{q_{t}^{n}}{d+\mu\left(g_{t}\right) w_{t}}, \quad \frac{1}{\underline{p}_{t}}=\frac{q_{t}^{n}}{\mu\left(g_{t}\right) w_{t}}
$$

Interest rates and investment are given by (3.11) and (3.13), respectively.

\subsection{Real Exchange Rate Variability}

We have seen that managers will take on dollar debt only if there is enough anticipated real exchange rate variability ((3.10) holds), so that there are high returns in the good state $\left(d_{t}=d\right)$ and a critical mass of insolvencies in the bad state $\left(d_{t}=0\right)$. We now reverse the question and ask instead when a risky debt structure implies that exogenous demand variability is translated into enough real exchange rate variability. In other words, we determine the conditions under which (3.10) holds at all times.

At time $t$, the expectation of $t+1$ 's prices determines investment and the amount of dollar debt $\left(I_{t}\right.$ and $\left.b_{t}\right)$. At $t+1, I_{t}$ and $b_{t}$ together with the agents' expectations of prices at $t+2$ will determine $t+1$ 's market clearing prices $\left(\bar{p}_{t+1}\right.$ and $\left.\underline{p}_{t+1}\right)$. Will these prices at $t+1$ validate time $t$ expectations under which $I_{t}$ and $b_{t}$ are selected? That is: $(i)$ will there be widespread insolvency in the 
bad state $\left(\pi\left(\underline{p}_{t+1}\right) \leq 0\right)$, so that it is possible to claim the subsidy implicit in the guarantee? ( $i i)$ will there be a sufficiently high return in the good state to ensure that the ex-ante expected return is high enough $\left(\alpha \theta \bar{p}_{t+1} / p_{t} \geq 1+r\right)$ ?

It turns out that in an RSE returns are determined by the evolution of net worth. To derive the law of motion of $w_{t}$ consider a typical period $t$ during which all inherited debt is denominated in dollars and agents know that at $t+1$ there can be a crisis with probability $1-\alpha$. In an RSE all incumbent managers are solvent in the good state, while all are insolvent in the bad state. Thus, in the good state the net worth of new managers is $\bar{w}_{t}=[1-c] \pi_{t}=[1-c]\left[p_{t} q_{t}-\left(1+\rho_{t}\right) b_{t}\right]$. In contrast, in the bad state, the new cohort starts out with $\underline{w}_{t}$ dollars. Market clearing equation (3.16) implies that $p_{t} q_{t}=d+\mu_{t} w_{t}$, while the interest rate and the credit equations (3.11) and (3.15) imply that the debt burden is $\left(1+\rho_{t-1}\right) b_{t-1}=$ $\alpha^{-1} h \mu_{t-1} w_{t-1}$. It follows that in an RSE $w_{t}$ evolves according to

$$
w_{t}= \begin{cases}\bar{w}_{t}:=\frac{(1-c) d}{1-\eta_{t}}-\frac{\eta_{t-1} h \alpha^{-1}}{1-\eta_{t}} w_{t-1} & \text { prob. } \alpha \\ \underline{w}_{t} & \text { prob. } 1-\alpha\end{cases}
$$

with initial conditions $q_{0}$ and $w_{0}$, and where the cash flow multiplier $\eta_{t}$ equals

$$
\eta_{t}:=(1-c) \mu_{t}<1
$$

We restrict $\eta_{t}<1$ so that (3.17) will be stable, which we require because we are interested in analyzing high frequency fluctuations around a steady state.

We can now determine when it is that (i) and (ii) above hold. Consider (i), the requirement of widespread insolvency in the bad state. If firms have dollar debt on the books, a bad demand shock can bankrupt them provided $p_{t}$ drops sufficiently. We show in the appendix that this is the case if and only if the aid payment satisfies: $\underline{w}_{t+1}<\frac{\mu_{t}}{\mu_{t+1}} \alpha^{-1} h w_{t}$, or equivalently

$$
\underline{w}_{t+1}=\omega \frac{h}{\alpha} \frac{\mu_{t}}{\mu_{t+1}} w_{t}, \quad \omega \in(0,1)
$$

A small enough $\underline{w}_{t}$ ensures that investment demand is small enough relative to the output of $\mathrm{N}$-goods to ensure that the price drops enough to bankrupt firms with dollar debt on the books.

With regards to question (ii) (sufficiently high ex ante returns), note that tomorrow's good state return $\theta \bar{p}_{t+1} / p_{t}$ will be greater than $1+r$ provided tomorrow's 
demand is sufficiently high relative to tomorrow's supply. Since tomorrow's investment demand is dependent on tomorrow's net worth, and tomorrow's supply is determined by today's investment (or equivalently, because of the borrowing constraints, by today's net worth), it is necessary that net worth be positive and that its growth rate $\left(w_{t+1} / w_{t}\right)$ be high enough. We show in the appendix that this is the case if and only if

$$
\bar{\eta} \frac{h}{\alpha}+[1-\bar{\eta}][1+r] \leq \frac{1}{\bar{\eta}}-1, \quad d>\frac{h}{\alpha} \bar{\eta} w_{0}, \quad \text { with } \quad \bar{\eta}:=\eta(g=1)
$$

The appendix shows that the restrictions we have imposed $((3.10),(3.18),(3.19)$ and $(3.20)$ ) can be simultaneously satisfied. This establishes the existence of a stable RSE.

Proposition 3.2 (Risky Symmetric Equilibrium (RSE)). Suppose systemic guarantees are generous $\left(g_{t}>\underline{g}\right)$ and crises are rare events $(\alpha>\underline{\alpha})$. There is a parameter region such that there exists a stable $R S E$. In this equilibrium:

- There is currency mismatch and crises occur with probability $1-\alpha$.

- Credit, the real exchange rate and net worth evolve according to (3.15), (3.16) and (3.17), respectively.

This proposition will be key to deriving our structural VARs. It has clear implications about the variables that must be included in a VAR, and for the ordering the variables need to have in order for the impulse response functions to be structurally interpretable.

\subsection{The Amplifying Mechanism}

Before turning to the derivation of the VARs we describe intuitively the amplification mechanism implied by Proposition 3.2. Suppose that the expected generosity of the guarantee $g_{t}$ falls permanently. ${ }^{19}$ Since lenders must break even, a lower $g_{t}$ is reflected in a higher lending rate $\rho_{t}$ via (3.11). A higher $\rho_{t}$, in turn, implies higher debt service costs, and thus more incentives to divert borrowed funds. This tightens the borrowing constraints faced by N-firms: at each level of net

\footnotetext{
${ }^{19}$ Recall that $g_{t}$ is the share of the outstanding debt that lenders expect to get repaid at $t+1$ by the government in case a meltdown takes place at $t+1$.
} 
worth $\left(w_{t}\right)$ N-firms can now borrow less and thus invest less (i.e., the investment multiplier $\mu_{t}$ falls). This is the direct effect of a $g$ shock on the economy.

There is, however, a second amplifying effect. It comes about because (i) the demand for $\mathrm{N}$-goods comes in part from the $\mathrm{N}$-sector itself and (ii) there is currency mismatch. The decline in demand for N-goods, generated by the reduction in $\mathrm{N}$ sector investment $\left(I_{t}\right)$, leads to a fall in the relative price of $\mathrm{N}$-goods $p_{t}$ (i.e., a real depreciation) so that the N-market clears. Since N-firms have dollar debt on the books, the real depreciation induces a fall in N-sector's profits and net worth. A vicious circle ensues as lower net worth leads to even lower investment, which in turn leads to a greater real depreciation and so on. This is the 'balance sheet effect' that amplifies the direct effect of an increase in the spread $\left(\rho_{t}-r\right)$ on credit $\left(b_{t}\right)$ and the real value of N-output $\left(p_{t} q_{t}^{n}\right)$.

Since T-sector agents have access to international capital markets and $r$ is unchanged, T-sector production is not directly affected by the increase in the spread. Thus, both the N-to-T output ratio $\left(p_{t} q_{t}^{n} / q_{t}^{t r}\right)$ and the growth rate of GDP $\left(p_{t} q_{t}^{n}+q_{t}^{t r}\right)$ fall..$^{20}$

Notice that the comovements along the transition path are consistent with those we documented in Section 2. An increase in the spread is associated with a fall in credit, the N-to-T output ratio and GDP growth. Furthermore, if the productivity parameter $\theta$ is not too big, there is also a real depreciation along the transition path. Notice that since domestic credit is allocated to credit constrained $\mathrm{N}$-firms, and their net worth falls together with $p_{t} q_{t}^{n}$, GDP growth falls by less than credit growth.

Another important implication is that the amplification mechanism is at work not only during the time that the shock occurs. It also reduces the steady state value of $b_{t}$ and $p_{t} q_{t}^{n}$ via (4.4). This implies that the balance sheet effect amplifies both the impact and the cumulative effects of a shock to the spread.

Two comments are in order. First, for the amplification mechanism to work it is essential that the economy be in an RSE. If there were no currency mismatch, demand risk would not be translated into insolvency risk. As a result, borrowers would never become insolvent, and shocks to the subsidy implicit in the guarantee would not affect the interest borrowers have to pay. Second, in an RSE the fall in $g_{t}$ does not lead to a crisis: in equilibrium the real depreciation is not large enough so as to bankrupt N-firms. This is important because we are characterizing high

\footnotetext{
${ }^{20}$ In an extended model $q_{t}^{t r}$ might increase if the decline in $p_{t} q_{t}^{n}$ comes about through a decline in $p_{t}$, and $\mathrm{N}$-goods are used in the production of T-goods.
} 
frequency (quarterly) fluctuations, not low frequency boom-bust cycles. Recall that in the model, crises can be caused only by demand shocks, and that these shocks must be rare events for an RSE to exist.

\section{Structural VARs}

Here we derive a set of structural VARs that link the spread to output, and take them to the data. Structural VARs can be derived directly from Proposition 3.2 because in an RSE the key variables follow a recursive autoregressive system. This will allow us to: (i) determine which variables can be included in a VAR; and (ii) identify the effects of structural shocks in the VARs we run.

We estimate four different VARs. One includes the spread, GDP and credit. The reaction of GDP and credit to the spread will illustrate the strength of the credit channel. In the second VAR we will include the N-to-T output ratio instead of GDP in order to see whether sectorial asymmetries play a significant role in the amplifying mechanism. The remaining two VARs are similar to the first two, except that we include the real exchange rate instead of credit to determine whether there is evidence of a balance sheet effect.

In choosing these specifications, we are mindful of the fact that MICs have in common the existence of systemic guarantees and of an asymmetry in financing opportunities. However, there is a wide variation across MICs in exchange rate regimes and in the prevalence of nominal rigidities. It was thus important that the VARs be robust to these institutional differences in order for them to apply across the set of MICs. An attractive property of the RSE is that it is characterized by variables for which the equilibrium values are independent of the exchange rate regime.

In subsections 4.1 and 4.2 we derive the structural VARs from Proposition 3.2. In subsection 4.3 we present the estimation results. Lastly, in subsection 4.4 we simulate the model, and show that the reactions of GDP and credit to a shock to the spread resemble the reactions found in the data.

\subsection{The Average Equilibrium Path}

In our model economy there are two types of shocks: to the expected generosity of the guarantee $\left(g_{t}\right)$ and to demand $\left(d_{t}\right)$. The former are high frequency shocks (quarterly) that induce movements in the spread, while the latter are low frequency shocks (periods of several years) that introduce the possibility of crises in 
equilibrium. Recall that infrequent $d$ shocks are necessary for currency mismatch to arise in equilibrium. Too few or too many $d$ shocks and the balance sheet effect would not exist. Rather than setting $d$ shocks to zero, we will derive the VARs by computing the mean equilibrium response to a $g$ shock with respect to the probability distribution of $d$ shocks. $^{21}$

Computing the average equilibrium path can, in principle, be cumbersome. An attractive feature of the RSE of Proposition 3.2 is that the probability of crisis equals a constant $1-\alpha$ regardless of the number of crises that have occurred in the past. ${ }^{22}$ Since we do not need to keep track of history, we can derive a simple VAR representation of the average equilibrium path followed by the key variables. We consider first the interest rate spread: $\rho_{t}-r$. During normal times, as well as during a crisis, the spread is determined by (3.11). Thus, in an RSE the average response of the spread is determined by (we will use ${ }^{\prec,}$ to denote average):

$$
\frac{1+\tilde{\rho}_{t}}{1+r}=\frac{1}{\alpha+(1-\alpha) g_{t}}
$$

The spread at time $t$ depends only on the generosity guarantee that is expected to be granted at $t+1$.

Since in an RSE crises occur with probability $\alpha$, it follows from (3.15) and (3.17) that the average path of credit is $\tilde{b}_{t}=\left[\alpha \bar{w}_{t}+[1-\alpha] \underline{w}_{t}\right]\left[\mu_{t}-1\right]$. In order to derive a dynamic system that can be estimated with observable data, we need to substitute away net worth $\left(\bar{w}_{t}\right.$ and $\left.\underline{w}_{t}\right)$. We do this by using (3.17) and (3.19). ${ }^{23}$ Thus, average credit is ${ }^{24}$

$$
\tilde{b}_{t}=\frac{\mu_{t}-1}{1-\alpha \eta_{t}}\left\{\alpha d[1-c]+b_{t-1}\left[1+\rho_{t-1}\right]\left[\frac{1-\alpha}{\omega \mu_{t}}-\alpha[1-c]\right]\right\}
$$

Average real GDP and the N-to-T output ratio are given by $\tilde{p}_{t} \tilde{q}_{t}^{n}+q_{t}^{t r}$ and $\tilde{p}_{t} \tilde{q}_{t}^{n} / q_{t}^{t r}$,

\footnotetext{
${ }^{21}$ In order to compute the equilibrium responses it would be easier to simply look at the path along which crises (and $d$ shocks) are assumed away. Unfortunately, this is not possible because it is precisely the expectation of a crisis what is necessary to induce agents to choose risky dollar debt. Risky debt is, in turn, necessary for our amplifying mechanism to work, and for shocks to $g_{t}$ to induce movements in the interest rate spread.

${ }^{22}$ Condition (3.19) is key for this result.

${ }^{23}$ In an RSE the debt burden equals $b_{t-1}\left[1+\rho_{t-1}\right]=\alpha^{-1} h \mu_{t-1} w_{t-1}$. It then follows from (3.19) that $\mu_{t} a_{t}=\omega b_{t-1}\left[1+\rho_{t-1}\right]$. Equation (4.2) follows directly.

${ }^{24}$ Since an RSE exists only if $\alpha$ is large and $\eta_{t}<1, \tilde{b}_{t}$ is strictly decreasing in the interest rate $\rho_{t}$ provided we set $\omega \in(0,1)$ large enough, which we are free to do.
} 
respectively. Since in an $\mathrm{RSE} \tilde{p}_{t} \tilde{q}_{t}^{n}=\frac{\mu_{t}}{\mu_{t}-1} \tilde{b}_{t}+\alpha d$, it follows that

$$
G \tilde{D} P_{t}=\frac{\mu_{t}}{\mu_{t}-1} \tilde{b}_{t}+\alpha d+q_{t}^{t r}, \quad N \tilde{/} T_{t}=\left[\frac{\mu_{t}}{\mu_{t}-1} \tilde{b}_{t}+\alpha d\right] \frac{1}{q_{t}^{t r}}
$$

Note that the exogeneity of $q_{t}^{t r}$ reflects the fact that the T-sector can finance itself in world markets. T-sector investment and output are therefore not directly affected by high frequency shocks to the domestic interest rate $\left(\rho_{t}\right)$ that leave the T-sector agents' cost of funds unchanged. ${ }^{25}$

\subsection{Identifying Structural Shocks}

Here, we ask which variables to include in the VARs and how to structurally identify the effects of shocks. Proposition 3.2 imposes unambiguous restrictions on the variables that can be included in a structural VAR. Given $\left(w_{t-1}, \rho_{t-1}, \rho_{t}\right)$, the equilibrium values of $b_{t}, p_{t} q_{t}^{n}$, and $w_{t}$ are linearly dependent. Thus, at most one of these three variables can be included in a VAR. It follows that the effect of the spread on output can be empirically specified in a three variable VAR consisting of: (i) $\rho_{t}-r$, (ii) either $b_{t}$ or $p_{t} q_{t}^{n}$, but not both; and (iii) either $G D P_{t}$ or $N / T_{t}$, but not both.

As mentioned above, none of the variables included in the VAR are affected by the exchange rate regime. The spread $\left(\rho_{t}-r\right)$ is a function of the expected generosity of the guarantee. The output measures, $G D P_{t}$ and $N / T_{t}$, depend on T-output $\left(q_{t}^{t r}\right)$ and the value of N-output $\left(p_{t} q_{t}^{n}\right)$. Credit $\left(b_{t}\right)$ and $p_{t} q_{t}^{n}$ depend on net worth and the spread.

To derive the VARs we will consider deviations from the 'lucky' steady state. The net worth's lucky steady state is the value to which $w_{t}$ converges along a path in which no crises occur and the guarantee rate is constant $(g)$. It follows from (3.17) that in a lucky steady

$$
w^{s s}(g)=\frac{1-c}{1-\eta(g)+\alpha^{-1} h \eta(g)} d
$$

Since $\eta(g)<1$, this steady state is stable. ${ }^{26}$ The levels of $b_{t}$ and $p_{t} q_{t}^{n}$ are deter-

\footnotetext{
${ }^{25}$ There might an indirect effect through $p_{t}$.

${ }^{26}$ To see this note that $w_{t}$ in $(3.17)$ converges to a steady state along the lucky path if and only if $\frac{\eta h \alpha^{-1}}{1-\eta}<1$. This condition is equivalent to $\eta<\frac{1}{1+\alpha^{-1} h}<1$.
} 
mined by plugging (4.4) into (3.15) and (3.16).

Consider an economy that is initially in a lucky steady state associated with an expected guarantee $g$, and suppose that at time $t$ it jumps to $g_{t}=g+u_{g, t}$. In order for the impulse responses to make sense, and for them to capture both tranquil time and crisis time reactions, it is necessary that: (i)an RSE exists for all possible values of the shock $u_{g, t}$, and (ii)shocks to $g_{t}$ alone do not lead to crisis. Proposition 3.1 implies that an RSE exists only if $g_{t}$ is large enough to ensure that the expected payoff associated with dollar debt is greater than or equal to that associated with peso debt (i.e., $\Pi_{t+1}^{r}\left(g_{t}\right) \geq \prod_{t+1}^{s}$ for all $t$ ). Thus, for (i) it is necessary to restrict the support of the shock: $u_{g, t} \in[\bar{u},-\bar{u}]$, where

$$
\bar{u}=1-g, \quad g=\frac{1+\underline{g}}{2}, \quad \text { and } \Pi_{t+1}^{r}(\underline{g}) \geq \Pi_{t+1}^{s}
$$

That is, $g_{t}$ can take values on $[g, 1]$. Requirement (ii) is ensured by the condition $\eta_{t}<1 .{ }^{27}$

\section{Identification}

A central problem in tracing the effects of a shock on the other variables is that VAR residuals are contemporaneously correlated. Thus, in order to uncover the structural shocks from the residuals of the reduced form estimation, we need identifying restrictions. A remarkable feature of the RSE is that it implies that the VARs we consider all have lower triangular structures, enabling us to recover the structural shocks. ${ }^{28}$

To structurally identify the VARs we use (4.1)-(4.3) to trace out the effects of a shock to $g_{t}$. Here, we will focus on the VAR that includes $b_{t}$ and $G D P_{t}$. Analogous arguments apply to the other VARs. First, since in an RSE the spread is affected only by $g_{t}$, a shock to $g_{t}$ can be viewed as a shock to the spread, $\rho_{t}-r$. Second, since the cash-flow $\left(\eta_{t}\right)$ and investment $\left(\mu_{t}\right)$ multipliers are given by $\eta_{t}=[1-c] \mu_{t}=\frac{1-c}{1-h \alpha^{-1}\left[1+\rho_{t}\right]^{-1}}$, it follows from (4.2) that average credit is contemporaneously affected only by the spread, through $\mu_{t}$ and $\eta_{t}$. Lastly, (4.3) implies that GDP and the N-to-T ratio are contemporaneously affected both by

\footnotetext{
${ }^{27}$ To see this suppose that $g_{t}=0$ and $d_{t}=d$, so that $\underline{p}_{t}=\frac{m_{t} w_{t}+d}{q_{t}}$. One can verify that at this low price $\pi\left(p_{t}\right)$ is positive.

${ }^{28} \mathrm{An}$ alternative approach for achieving identification is to place restrictions on the long run behavior of the variables or estimating the response functions of central banks to shocks in output.
} 
shocks to credit and to the spread (through $\mu_{t}$ ). Put slightly differently, (4.1)-(4.3) imply the following log-linear representation of the average responses to a shock in $g_{t}: 29$

$$
\begin{aligned}
\widetilde{A}_{0} Y_{t} & =\widetilde{A}_{1} Y_{t-1}+u_{t}, \quad \text { where } \\
Y_{t} & =\left(\begin{array}{c}
d\left(\rho_{t}-r\right) \\
d\left(\hat{b}_{t}\right) \\
d\left(G \hat{D} P_{t}\right)
\end{array}\right), \quad \widetilde{A}_{0}=\left[\begin{array}{ccc}
1 & 0 & 0 \\
-\delta_{21} & 1 & 0 \\
-\delta_{31} & -\delta_{32} & 1
\end{array}\right] \quad \text { and } u_{t}=\left(\begin{array}{c}
u_{\rho-r, t} \\
u_{b, t} \\
u_{q, t}
\end{array}\right),
\end{aligned}
$$

where a hat denotes logarithm. In practice, we cannot estimate this structural model directly. Instead, we estimate a reduced form. ${ }^{30}$ For this reduced form to be structurally identified, it is necessary that the matrix $\widetilde{A}_{0}$ is lower triangular. ${ }^{31}$

The lower triangular structure of $\widetilde{A}_{0}$ determines the VAR ordering $\left(\rho_{t}-\right.$ $\left.r, b_{t}, G D P_{t}\right)$ and allows us to compute impulse response functions that are structurally identified. Again, the key point is that this ordering follows directly from the model, as $\rho_{t}-r$ is only affected by shocks to $g_{t}, b_{t}$ is contemporaneously affected only by the spread, while $G D P_{t}$ (or $N / T_{t}$ ) is affected by the other two variables in the same period.

${ }^{29}$ The structural residuals $u_{t}$ are by assumption uncorrelated and have zero mean: $E\left(u_{t}\right)=0$ and $E\left(u_{t}, u_{t}^{\prime}\right)=\widetilde{\Delta}$, where $\tilde{\Delta}$ is a matrix with the variances of the shocks on the main diagonal and zero elements otherwise. Notice that $u_{\rho-r, t}$ reflects shocks to $g, u_{b, t}$ can reflect shocks to $c$ or $\omega$, and $u_{q, t}$ can reflect shocks to $q_{t}^{t r}$.

${ }^{30}$ These equations can be viewed as a restricted version of the following more general system of equations: $\widetilde{A}_{0} Y_{t}=\widetilde{A}_{1} Y_{t-1}+\ldots+\widetilde{A}_{j} Y_{t-j}+u_{t}$. We estimate the following reduced form of the model:

$$
\begin{aligned}
Y_{t} & =\widetilde{A}_{0}^{-1} \widetilde{A}_{1} Y_{t-1}+\ldots+\widetilde{A}_{0}^{-1} \widetilde{A}_{p} Y_{t-p}+\widetilde{A}_{0}^{-1} u_{t} \\
& =A_{1} Y_{t-1}+\ldots+A_{p} Y_{t-p}+\varepsilon_{t}, \text { where } A_{i}=\widetilde{A}_{0}^{-1} \widetilde{A}_{1}
\end{aligned}
$$

${ }^{31}$ The relationship between the structural residuals $u_{t}$ and the reduced form residuals $\varepsilon_{t}$ from the estimated regression equation is: $\varepsilon_{t}=\widetilde{A}_{0}^{-1} u_{t}$, with $E\left(\varepsilon_{t}\right)=0$ and $E\left(\varepsilon_{t}, \varepsilon_{t}^{\prime}\right)=$ $E\left(\widetilde{A}_{0}^{-1} u_{t} u_{t}^{\prime} \widetilde{A}_{0}^{-1 \prime}\right)=E\left(\widetilde{A}_{0}^{-1} \widetilde{D} \widetilde{A}_{0}^{-1 \prime}\right)=\Omega$. As $\Omega$ is symmetric and positive semi-definite, we can use a Choleski decomposition to uncover the structural residuals from the estimated reduced form residuals. This is because for any symmetric and positive semi-definite matrix $\Omega$, there exists a triangular Matrix $C$, with ones on the main diagonal, such that $\Omega=C D C^{\prime}$. In our case $D=\widetilde{D}$ and $C=\widetilde{A}_{0}^{-1}$. 
Notice that the ordering of the variables is different than in the literature, where the interest rate and the spread are typically placed in the last position of the VAR. The rationale for this ordering is that if the central bank has full control over short-term rates, it can immediately adjust them in response to an output shock. Thus, interest rates can be contemporaneously affected by output in quarterly data. While this might be the case in countries such as the US, it is not so in MICs. In MICs, standard monetary instruments, like open market operations, have little leeway in affecting the interest rates that determine investment. Thus, output does not have a contemporaneous effect on the spread. ${ }^{32}$

In MICs, shocks to the spread $\rho_{t}-r$ are more appropriately viewed as shocks to agents' expectations about the willingness and the ability of the government to guarantee loans. These, in turn, are determined by, among other things, the fiscal stance of the government, its access to international credit lines, and the willingness of politicians to grant bailouts. ${ }^{33}$

\subsection{Impulse Response Functions}

We estimate the VARs in first differences using quarterly data for 8 MICs (Argentina, Brazil, Chile, Korea, Mexico, Peru, Thailand and Turkey) and the G3 countries (Germany, Japan and the United States), and compute the impulse response functions corresponding to a shock to the spread. ${ }^{34}$ We include two lags and a time trend in the estimation. As we reject the null of cointegration among the variables after finite sample adjustment, we do not include an error correction term. ${ }^{35}$ In order to represent the impulse response functions in a visually illustrative way, we show the grouped impulse response functions that show the average behavior of the 8 countries -a representation also used in Bekaert and Campbell (2001).

\footnotetext{
${ }^{32}$ In the literature for high income countries, the ordering is not uncontroversial. For instance, Sims (1980) orders the interest rate in the first position of the VAR.

${ }^{33}$ Brazil in the year 2002 exemplifies this situation. The increase in the likelihood that a leftist candidate might win the Presidential elections lead to skyrocketing interest rates. The bailout program announced by the IMF in August lead to a reduction in the premium. Unfortunately this lasted only a few days.

${ }^{34}$ The selection of countries is determined by the availability of quarterly data, in particular at the sectorial level. We have included countries for which we have at least 7 years of quarterly data for all variables. Note that the length of the VAR is not the same across countries. See the Appendix for variable definitions and data sources.

${ }^{35}$ According to the finite sample critical values reported in Cheung and Lai (1993).
} 
VAR I: $\left(\rho_{t}-r, b_{t}, G D P_{t}\right)$

This VAR addresses the existence and strength of the credit channel. Figure 4.1 traces the cumulative response of GDP and credit to a one-standard deviation shock in the spread. Shown are four cumulative impulse response functions corresponding to: an average of the $8 \mathrm{MICs}$, an average of the G3, Mexico and the US.

We can see that in the group of $8 \mathrm{MICs}$ both variables respond negatively to the shock. By contrast, in the G3 the responses are an order of magnitude smaller, although they have the same sign. Panel (c) shows the point estimates and standard errors for the cases of Mexico and the United States. Here again, we see that the response in Mexico is much larger than in the US. Furthermore, the responses in Mexico are significant at the $5 \%$ level, while the ones in the US are not. ${ }^{36,37}$

\footnotetext{
${ }^{36}$ Note that although we do not report standard errors, the responses of the group of 8 MICs are statistically highly significant. As we have an average of 8 countries, the standard errors of the individual countries would have to be divided by $\sqrt{8}$ to evaluate the significance level. Thus, even if the point estimates were smaller than the standard errors individually, the grouped impulse responses would still be significant.

${ }^{37} \mathrm{As}$ an alternative we could have included dummies to capture an increase in the spread due to a crisis. If we were to do so, the main results would not change. Although the effect during crisis times is stronger, the total cumulative effect is only a bit smaller if the dummy is included (23\% in the case of Mexico).
} 
Figure 4.1: VAR I: $\left(\rho_{t}-r, b_{t}, G D P_{t}\right)$

Panel (a): Middle Income Countries

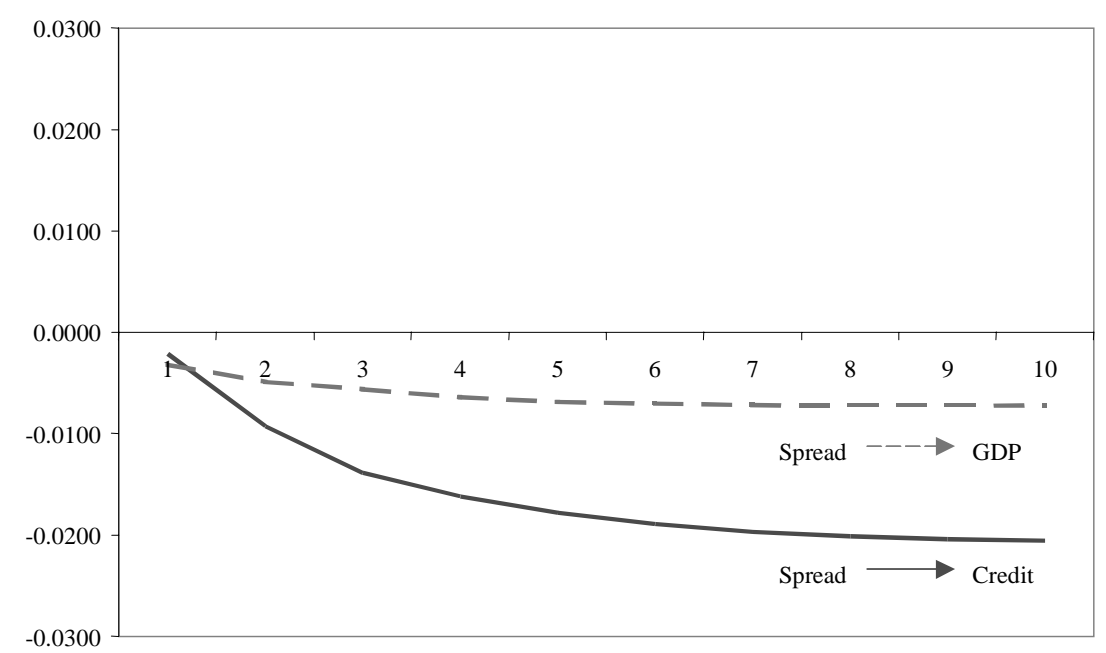

Note: The lines trace the accumulated average response of 8 countries to a one-standard deviation shock. Calculations are based on three-variable VARs including the spread, credit and GDP. Each VAR is estimated from quarterly data in growth rates, allowing for 2 lags and a time trend.

\section{Panel (b): High Income Countries}

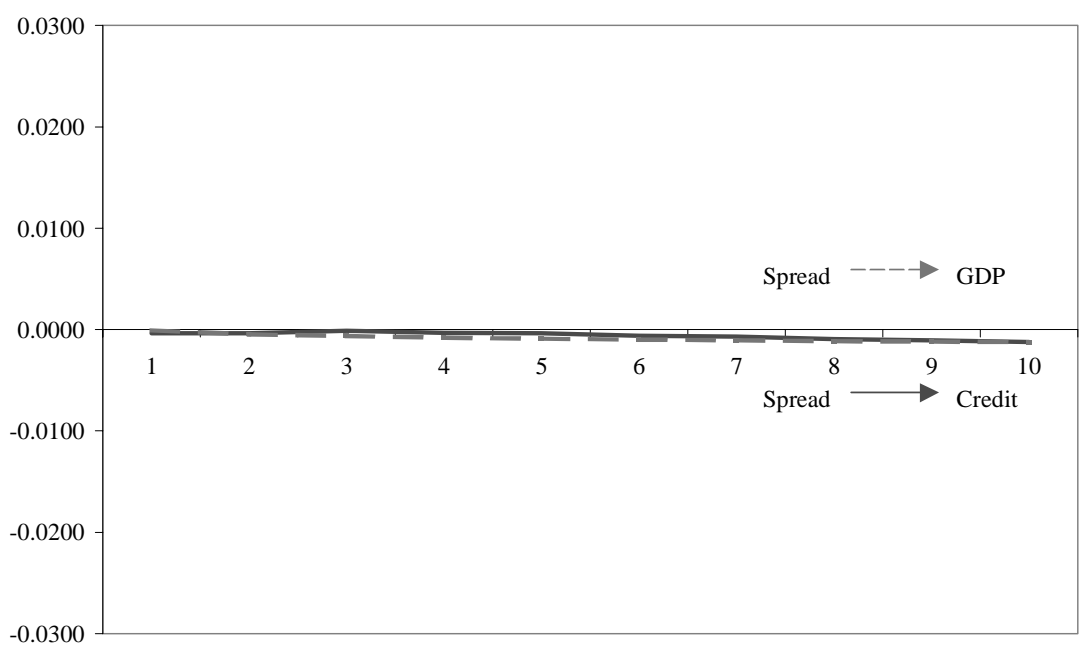

Note: The lines trace the accumulated average response of 3 countries to a one-standard deviation shock. Calculations are based on three-variable VARs, specified as in panel (a). 
Panel (c): Mexico vs. USA

Mexico

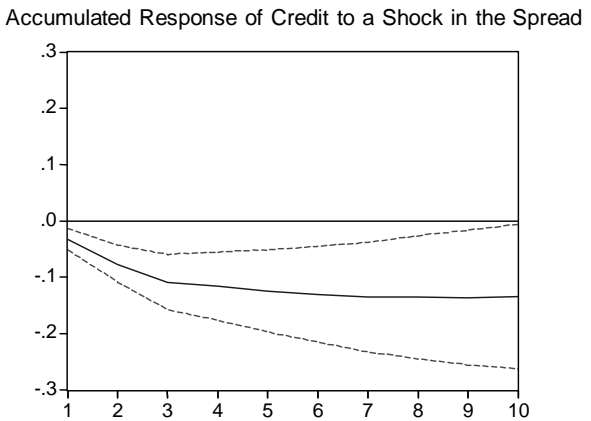

Accumulated Response of GDP to a Shock in the Spread

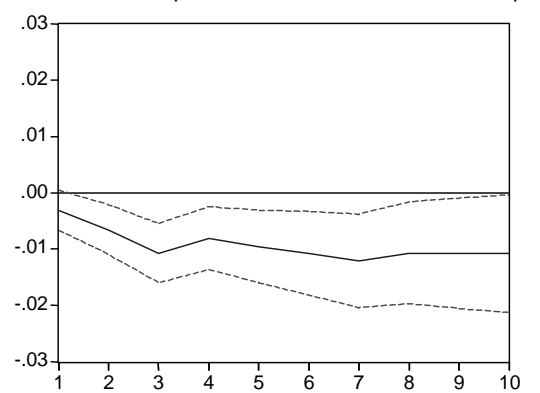

USA

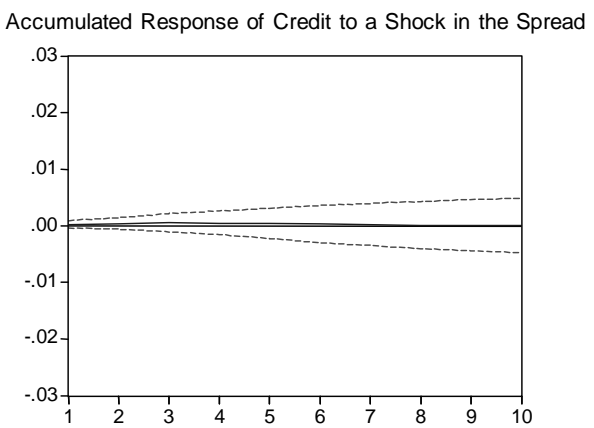

Accumulated Response of GDP to a Shock in the Spread

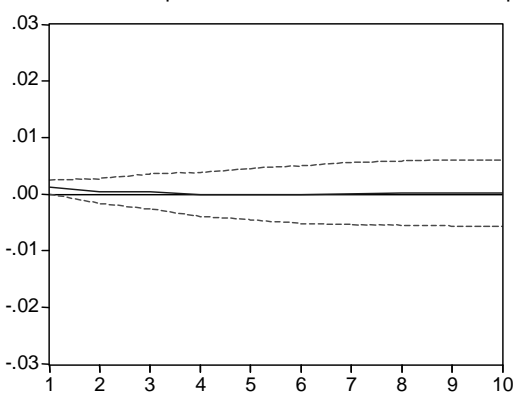

Note: The lines trace the accumulated response of Mexico and the USA to a one-standard deviation shock. Calculations are based on three-variable VARs, specified as in panel (a). Finite sample critical values are generated by 1000 Monte Carlo replications.

This result establishes the first of our main empirical findings, that the credit channel is strong in MICs: GDP reacts strongly to the interest rate spread. It also provides a hint as to the amplifying mechanism, as credit also reacts strongly to the spread. In fact, it reacts more strongly than GDP. This observation is consistent with any model with a financial accelerator. However, at this point, we cannot discern any specific amplifying mechanism. The next group of VARs will help us uncover the mechanism that generates the strong credit channel. 
Figure 4.2: VAR II: $\left(\rho_{t}-r, b_{t}, p_{t} q_{t}^{n} / q_{t}^{t r}\right)$

\section{Panel (a): Middle Income Countries}

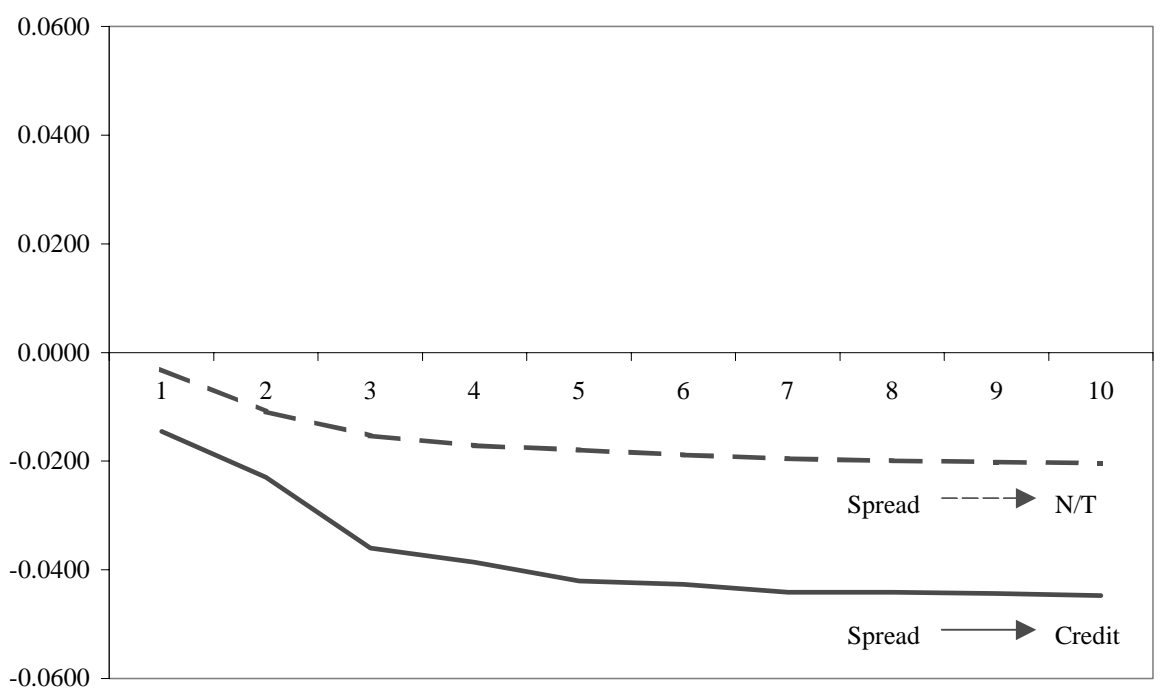

Note: The lines trace the accumulated average response of 8 countries to a one-standard deviation shock. Calculations are based on three-variable VARs including the spread, credit and N/T. Each VAR is estimated from quarterly data in growth rates, allowing for 2 lags and a time trend.

Panel (b): High Income Countries

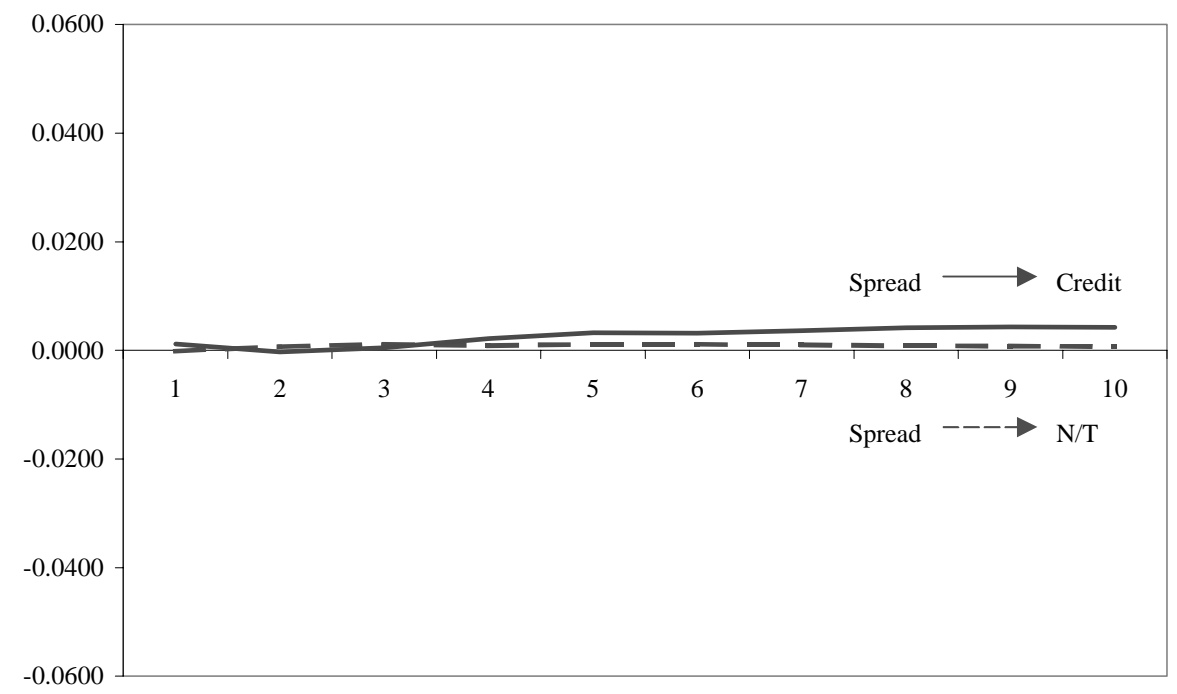

Note: The lines trace the accumulated average response of 3 countries to a one-standard deviation shock. Calculations are based on three-variable VARs, specifigd as in panel (a). 
Panel (c): Mexico vs. USA

Mexico

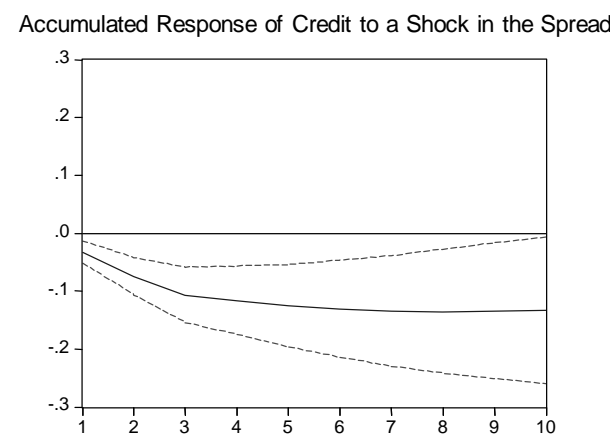

Accumulated Response of $\mathrm{N} / \mathrm{T}$ to a Shock in the Spread

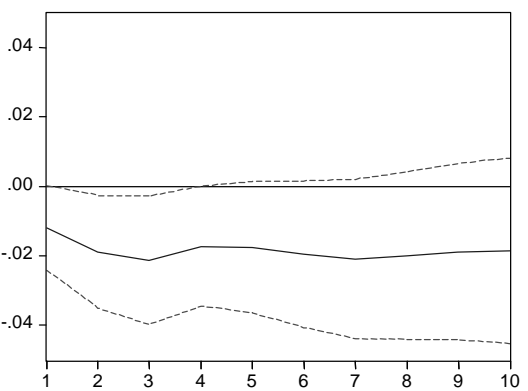

USA

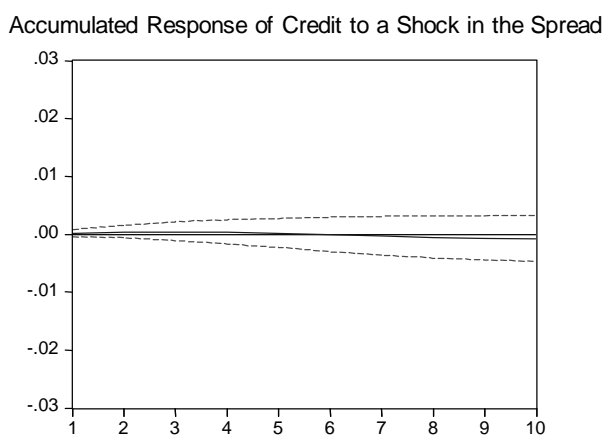

Accumulated Response of $\mathrm{N} / \mathrm{T}$ to a Shock in the Spread

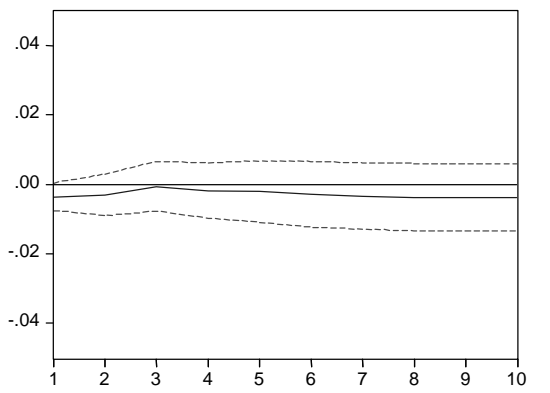

Note: The lines trace the accumulated response of Mexico and the USA to a one-standard deviation shock. Calculations are based on three-variable VARs, specified as in panel (a). Finite sample critical values are generated by 1000 Monte Carlo replications.

VAR II: $\left(\rho_{t}-r, b_{t}, p_{t} q_{t}^{n} / q_{t}^{t r}\right)$.

This VAR allows us to analyze the credit channel from a different angle, and see whether sectorial asymmetries play a significant role in the amplifying mechanism. It will permit us to discriminate between our model and other possible mechanisms. Panel (a) of Figure 4.2 shows that in MICs there is indeed a striking asymmetry in the response of the $\mathrm{N}$ and $\mathrm{T}$ sectors. In response to a positive shock in the spread, credit and the N-to-T output ratio decline. Panel (b) shows that this amplifying mechanism is indeed a phenomenon particular to MICs, as we do not see a similar pattern in the G3. Panel (c) shows the impulse response functions for Mexico and the US. Here again, the reaction of credit and N/T are statistically significant in Mexico, but not in the USA. 
The fact that credit and the N-to-T output ratio fall in response to the shock indicates that the N-Sector is more credit constrained than the T-Sector. In fact, the same conclusion can be drawn from VAR I as credit falls more than GDP. The negative GDP response is driven mainly by the decline in the N-Sector, while the T-sector is either only mildly affected or responds positively to the spread.

Combining these two results establishes our second main finding, that an asymmetry in sectorial responses is a key element of the amplifying mechanism. Any model that aims to explain the strength of the credit channel in MICs needs also to explain the striking asymmetry in sectorial responses. In the mechanism we propose it is caused by an asymmetry in financing opportunities, which also explains the strength of the credit response relative to that of GDP.

VARs III : $\left(\rho_{t}-r, 1 / p_{t}, G D P_{t}\right)$ and $\left(\rho_{t}-r, 1 / p_{t}, N / T_{t}\right)$.

Estimating VARs that include the real exchange rate $\left(1 / p_{t}\right)$ allows us to analyze more directly the role played by the balance sheet effect in amplifying the direct effect of the spread on output. Can one derive such VARs from Proposition 3.2? Should credit also be included? What is the correct ordering? Recall that an RSE can be characterized in terms of either $\left(w_{t-1}, \rho_{t-1}, \rho_{t}, b_{t}\right)$ or $\left(w_{t-1}, \rho_{t-1}, \rho_{t}, p_{t} q_{t}^{n}\right)$. Furthermore, since in the model $\mathrm{N}$-output is determined by past investment $\left(q_{t}^{n}=\theta I_{t-1}\right)$, the contemporaneous response of $p_{t}$ is the same as that of $p_{t} q_{t}^{n}$. Given this identification restriction, Proposition 3.2 implies that we should substitute the real exchange rate $\left(1 / p_{t}\right)$ for credit $\left(b_{t}\right)$ in VARs I and II. Empirically, we are assuming that $\mathrm{N}$-output is predetermined in a given quarter.

Figure 4.3 exhibits the cumulative impulse responses associated with the VAR $\left(\rho_{t}-r, 1 / p_{t}, G D P_{t}\right)$. For the group of MICs there is a decline in GDP and a real depreciation in response to a positive shock to the spread. In the G3, however, this response is absent. The graphs for Mexico and the U.S. replicate the same patterns.

Figure 4.4 corresponds to a VAR that includes the N-to-T output ratio instead of GDP. Here again we see a clear asymmetric response of the two sectors in the group of MICs and in Mexico. However, such an asymmetry is absent in the grouped responses of the G3 and in the US. 
Figure 4.3: VARs IIIa: $\left(\rho_{t}-r, 1 / p_{t}, G D P_{t}\right)$

\section{Panel (a): Middle Income Countries}

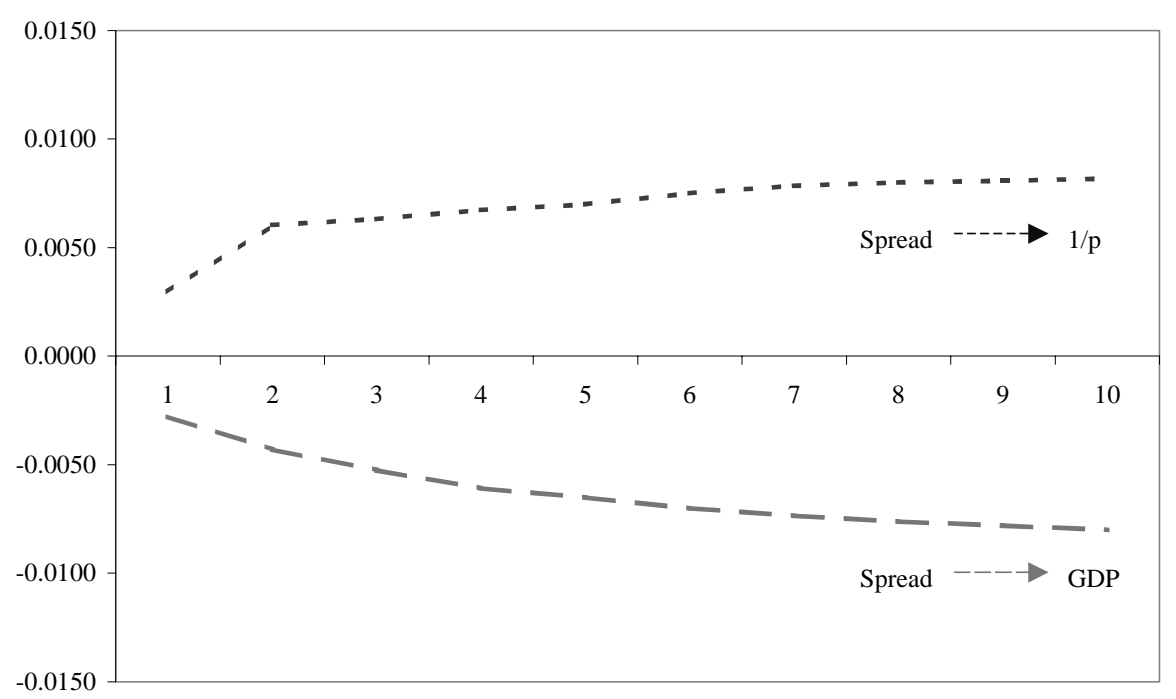

Note: The lines trace the accumulated average response of 8 countries to a one-standard deviation shock. Calculations are based on three-variable VARs including the spread, 1/p and GDP. Each VAR is estimated from quarterly data in growth rates, allowing for 2 lags and a time trend.

\section{Panel (b): High Income Countries}

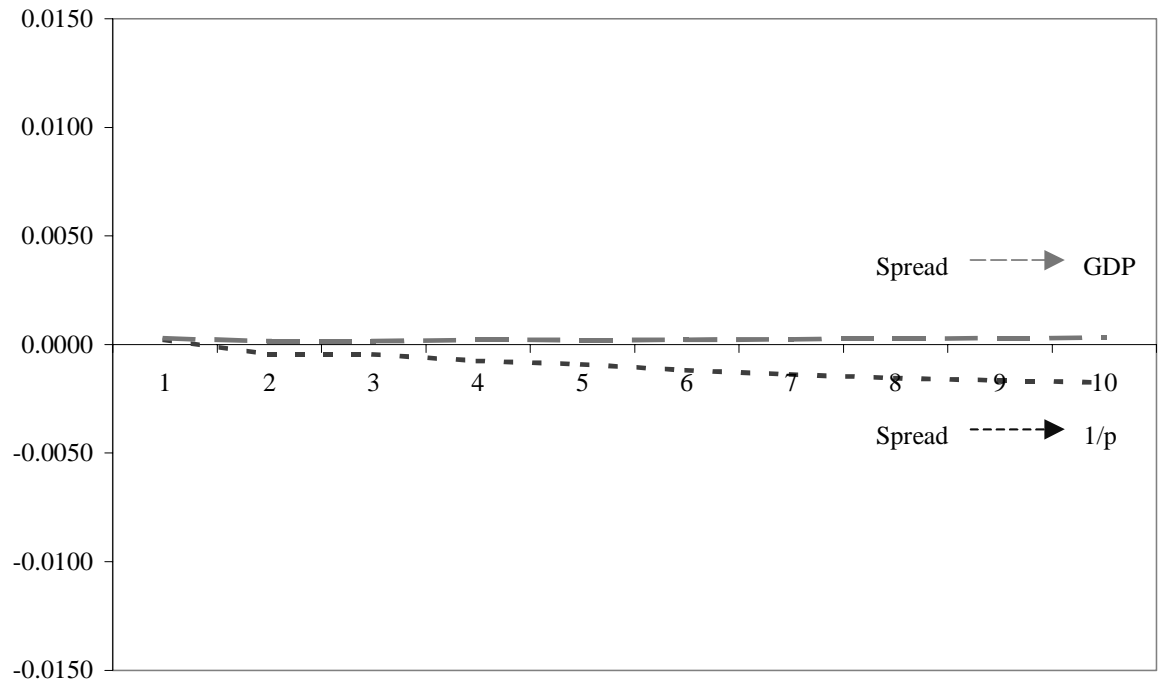

Note: The lines trace the accumulated average response of 3 countries to a one-standard deviation shock. Calculations are based on three-variable VARs, specifïll as in panel (a). 
Panel (c): Mexico vs. USA

Mexico

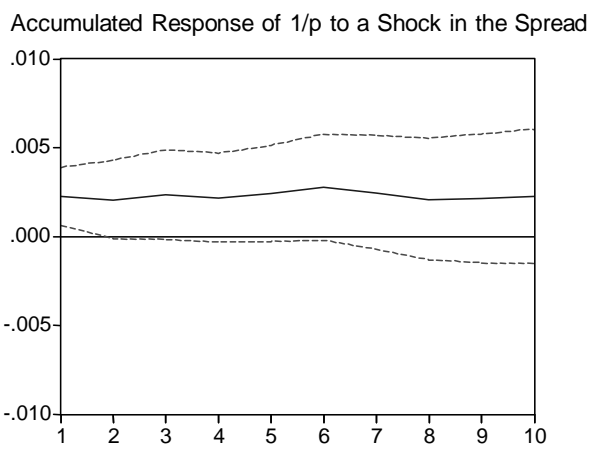

Accumulated Response of GDP to a Shock in the Spread

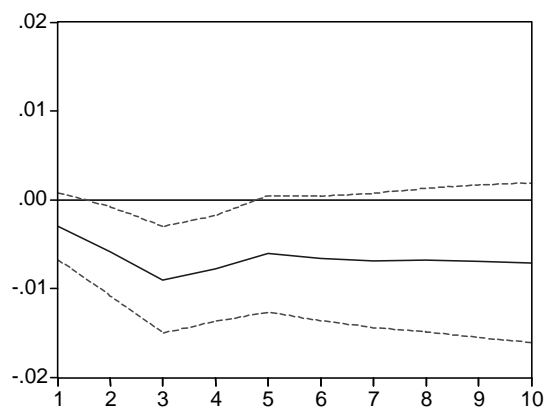

USA

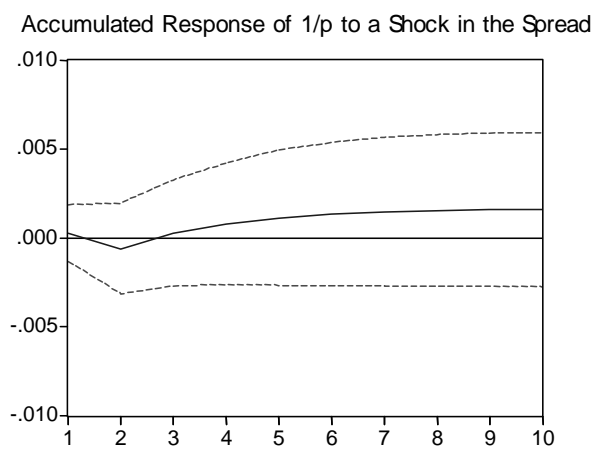

Accumulated Response of GDP to a Shock in the Spread

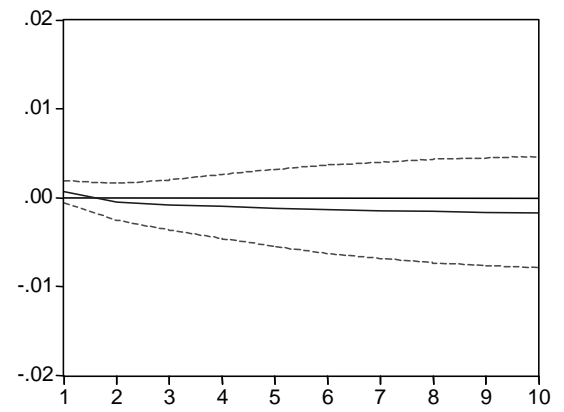

Note: The lines trace the accumulated response of Mexico and the USA to a one-standard deviation shock. Calculations are based on three-variable VARs, specified as in panel (a). Finite sample critical values are generated by 1000 Monte Carlo replications.

We take the significant real depreciation in response to an increase in the spread as an indication that currency mismatch is a key ingredient of the amplifying mechanism. The balance sheet effect is at work: after the initial decline in Ninvestment, the real depreciation reduces the net worth of $\mathrm{N}$-agents with dollar debt on the books. This reduction allows them to invest even less, and so on. Of course, we are not ruling out alternative mechanisms, but are not aware of any that are consistent with all of these facts. 
Figure 4.4: VARs IIIIb: $\left(\rho_{t}-r, 1 / p_{t}, N / T_{t}\right)$

\section{Panel (a): Middle Income Countries}

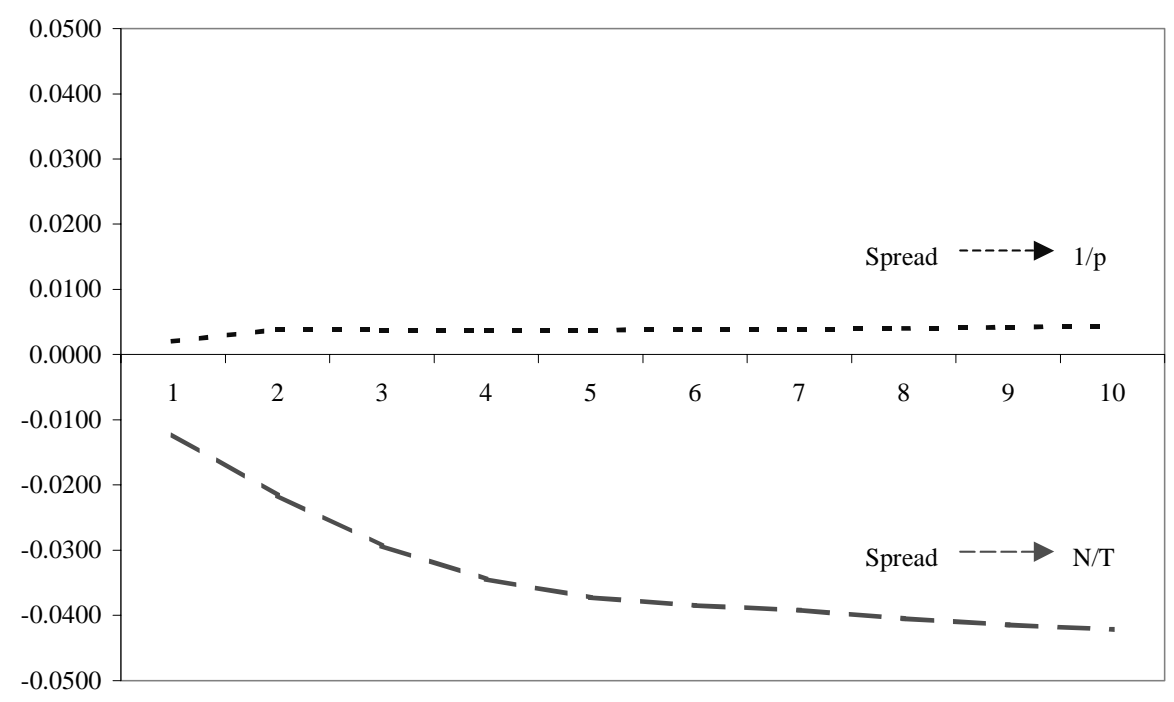

Note: The lines trace the accumulated average response of 8 countries to a one-standard deviation shock Calculations are based on three-variable VARs including the spread, 1/p and N/T. Each VAR is estimated from quarterly data in growth rates, allowing for 2 lags and a time trend.

\section{Panel (b): High Income Countries}

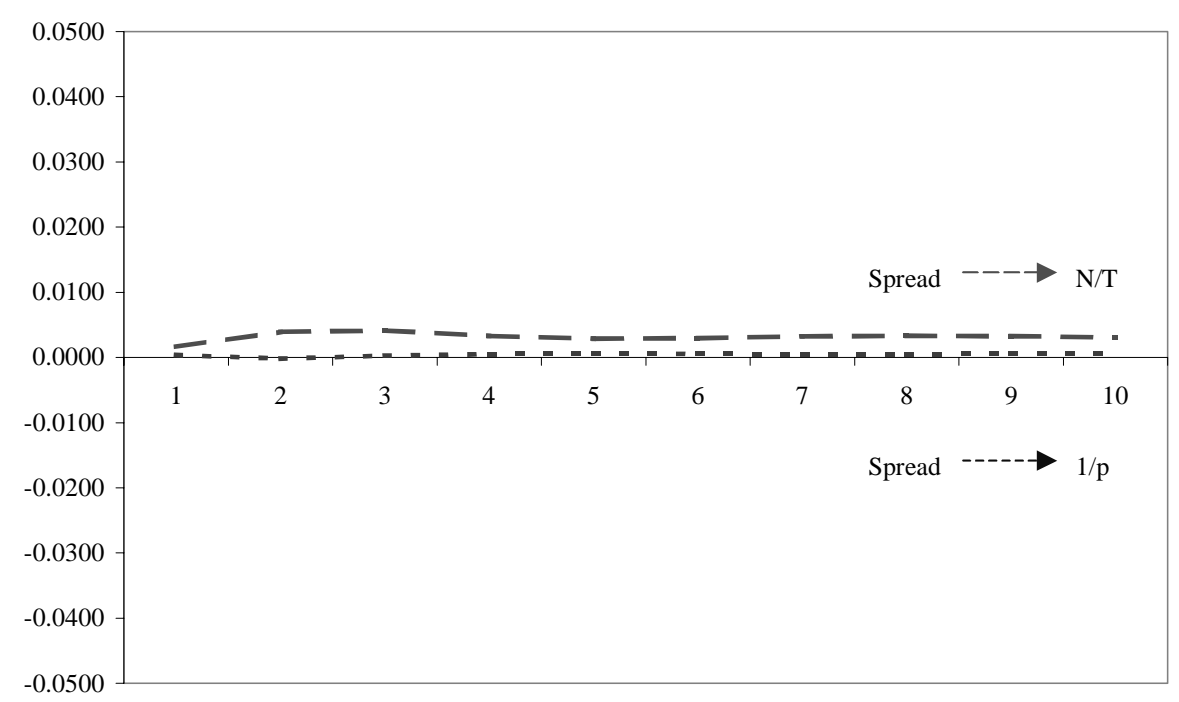

Note: The lines trace the accumulated average response of 3 countries to a one-standard deviation shock. Calculations are based on three-variable VARs, specified as in panel (a). 
Panel (c): Mexico vs. USA

Mexico

Accumulated Response of $1 / p$ to a Shock in the Spread

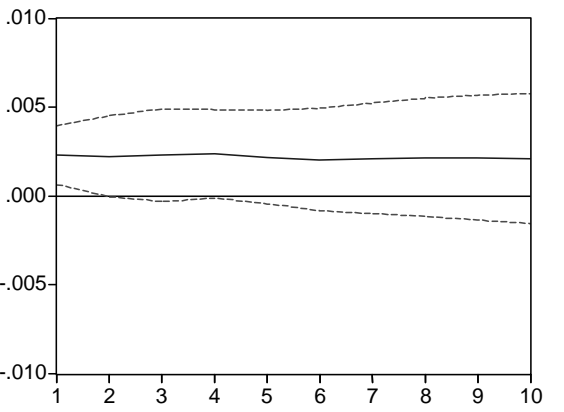

Accumulated Response of $\mathrm{N} / \mathrm{T}$ to a Shock in the Spread

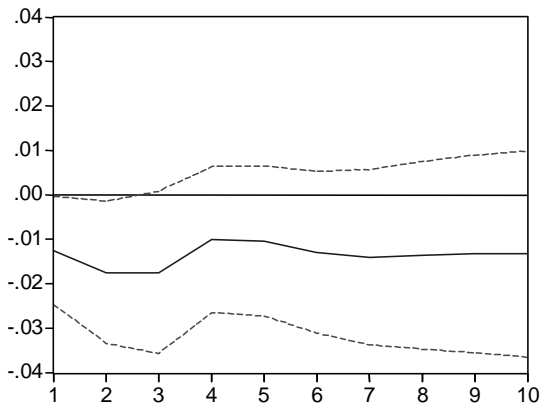

USA

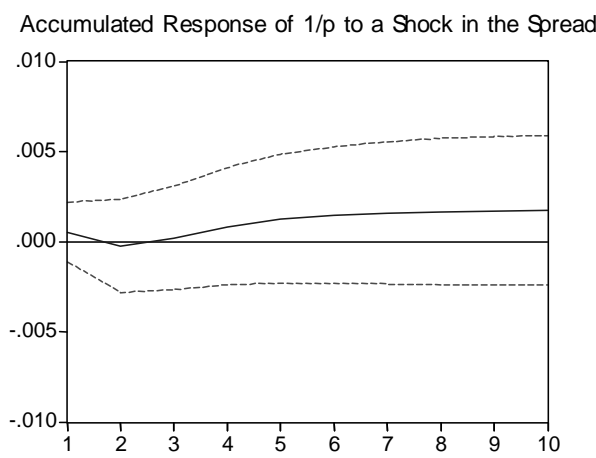

Accumulated Response of $\mathrm{N} / \mathrm{T}$ to a Shock in the Spread

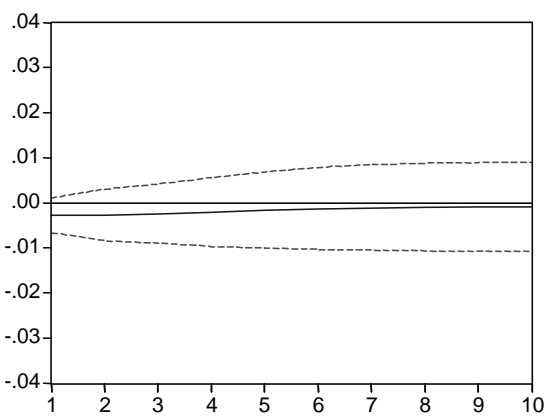

Note: The lines trace the accumulated response of Mexico and the USA to a one-standard deviation shock. Calculations are based on three-variable VARs, specified as in panel (a). Finite sample critical values are generated by 1000 Monte Carlo replications.

\subsection{Simulation of the Model}

We now contrast the VAR impulse responses to a simulation of the average response of our model economy along the equilibrium path (4.1)-(4.3).

To simulate the model we need to choose the value of eight parameters $(\alpha, r, c, h, d, g, \theta, \omega)$, and the initial conditions $\left(w_{0}, q_{0}\right)$. First, $\alpha$ and $r$ come from the data. In the panel of 39 MICs studied by Tornell and Westermann (2002) the probability of crisis in a given period is 0.05 . Thus, we set $\alpha=0.95$. We set the world interest rate $r$ equal to the average US interest rate over the period 1980:1 to 1999:4, which is equal to 0.075 . Second, we choose $c, \omega, d$ and $h$ so that the restrictions necessary for an RSE (i.e., (3.10), (3.19) and (3.20)) are satisfied: $c=0.6, \omega=0.1, d=10$ 
Figure 4.5: Simulation

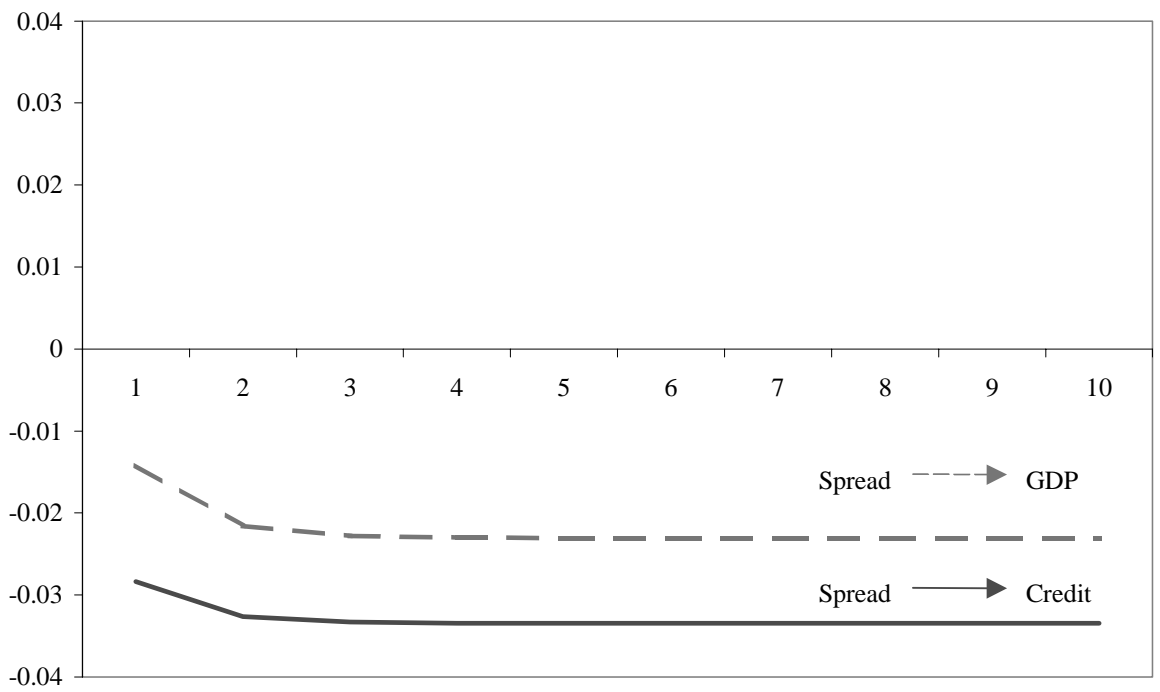

and $h=0.3$. Third, we set the generosity of the guarantee $g$ large enough to ensure that $\Pi_{t+1}^{d l r}>\Pi_{t+1}^{p s}(g=0.75)$. Forth, productivity parameter $\theta$ determines how an increase in the real value of N-output $p_{t} q_{t}^{n}$ is translated into changes in $p_{t}$ and $q_{t}^{n}$. We set $\theta=2$ so that $p_{t}$ is increasing. Lastly, the values of $\left(w_{0}, q_{0}\right)$ are neither critical for the existence of an RSE, nor determine the shape of the impulse responses.

Figure 4.5 shows the reaction of $G D P$ and $b_{t}$ to a negative shock to $g_{t}$ (it declines from 0.75 to 0.6 , which is equivalent to an increase in $\rho_{t}$ from 0.088 to 0.096). As the figure shows, the reaction patterns in the model and in the data look strikingly similar. ${ }^{38}$

The existence of an RSE and the simulated impulse responses are robust to alternative choices of the parameters. For instance, given all other parameter choices, ((3.10), (3.19) and (3.20)) are satisfied for any $h \in(0, .35)$ and any $c \in(.55,1)$. Furthermore, $g$ can be set anywhere from 0.06 to 1 .

\footnotetext{
${ }^{38}$ The figure displays the even periods of the response. Due to the negative coefficient on $w_{t-1}$, the system oscillates towards the new steady state. This is a particularity of the discrete nature of the model. It would not arise in a continuos time setup.
} 
Table 5.1: Sectorial and Size Distributions of Firms

\begin{tabular}{ccc}
\hline \hline & N-Sector & T-Sector \\
\cline { 2 - 3 } Small & $68 \%$ & $32 \%$ \\
Large & $33 \%$ & $67 \%$ \\
\hline \hline
\end{tabular}

Source: World Business Environment Survey (WBES), 2001.

Note: "small" corresponds to firms with up to 200 employees.

\section{Credit Market Imperfections}

Here we present evidence on the two key distortions that underlie the amplification mechanism: systemic guarantees and asymmetric financing opportunities. ${ }^{39}$

\section{Asymmetric Financing Opportunities Across Sectors}

We use firm level data from a panel of 3877 firms of the World Business Economic Survey of the World Bank (WBES, 2001). It covers 27 out of our sample of 39 MICs. ${ }^{40}$ The survey classifies firms according to their size and, among other things, firms were asked whether or not they export. Since the share of T-output in the group of export firms is greater than that of non-export firms, we identify exporters with T-sector firms and non-exporters with N-sector firms. Using this classification we can see in Table 5.1 that a majority (68 percent) of small and medium firms belongs to the N-sector, while a majority (67 percent) of large firms belongs to the T-sector. ${ }^{41}$

Firms were also asked to rank, on a scale from 1 to 4 , how much of an obstacle financing was to running their business. We use the answers from this survey to estimate an ordered probit model to assess whether there exists an asymmetry in

\footnotetext{
${ }^{39}$ In a previous version, we present evidence on the existence of currency mismatch. It is available from the authors upon request.

${ }^{40}$ Argentina, Brazil, Chile, Czech Republic, Ecuador, Egypt, Estonia, Hungary, Indonesia, Lithuania, Mexico, Malaysia, Peru, Philippines, Poland, Portugal, Russia, Slovakia, Slovenia, South Africa, Spain, Sweden, Thailand, Turkey, Tunisia, Uruguay and Venezuela. Schiffer and Weder (2001) describe in detail this data base. It is available from the World Bank at: http://www.worldbank.org/beext/resources/assess-wbessurvey-alt.htm

${ }^{41}$ There are some large firms in the N-sector, such as utilities. However, in most countries they represent a small share of the $\mathrm{N}$-sector firms in the survey.
} 
financing opportunities across the $\mathrm{N}$ and T-sectors. ${ }^{42,43}$

We create a dummy variable for the yes-or-no answer "do you export?" A significant positive parameter on the dummy indicates that $\mathrm{N}$-sector firms evaluate the access to finance as a significantly larger obstacle to running their business than T-sector firms do. Table 5.2 reports the regression results: regression 1 is the basic regression where we regress the perceived credit constraints on the $\mathrm{N}$ sector dummy. Regression 2 replaces the N-Sector by a variable that measures the percentage of output that is exported among exporters. Regression 3 reports the results of a regression that differentiates between small and large N-firms, and includes the age of the firm and the share of government participation as control variables.

In all regressions we find that there is a significant difference between exporters and non-exporters in their evaluation of financing as an obstacle for running their businesses. The latter evaluate the obstacle to be more severe. Furthermore, we find that among exporters, the larger the share of exports in output, the less significant is financing deemed to be as an obstacle for running a business. We also find that older firms have easier access to financing than younger firms. The same is true for firms with a high government participation. None of the control variables, however, obviates the role of the exporters/non-exporters indicator.

${ }^{42}$ We estimate ordered probit regressions of the following form.

$$
\begin{aligned}
y_{i}^{*} & =\beta_{0}+\beta_{1} E X P O R T+\beta_{2} A G E+\beta_{3} G O V+\gamma_{1} d_{1 i}+\ldots+\gamma_{n} d_{n i}+\varepsilon_{i}, \\
\text { where } y_{i} & =\left\{\begin{array}{lll}
1 & \text { if } & y_{i}^{*}<\alpha_{1} \\
2 & \text { if } & \alpha_{1}<y_{i}^{*}<\alpha_{2} \\
3 & \text { if } & \alpha_{2}<y_{i}^{*}<\alpha_{3} \\
4 & \text { if } & \alpha_{4}<y_{i}^{*}
\end{array}\right\},
\end{aligned}
$$

$\mathrm{n}=27$, and EXPORT is either a dummy that takes the value of 1 if the firm does not export, or it is the share exports in output among exporting firms. GOV controls for government participation in the firm, $A G E$ denotes the year a firm was established and $d_{1} \ldots d_{n}$ are country dummies. The dependent variable, $y$, captures the ranking of the severity of an obstacle for running a business, as perceived by the firms. The obstacles considered are financing, collateral and the exchange rate. The true y is not directly observed and the $\alpha$ parameters are estimated together with $\beta_{0} \ldots \beta_{3}$ and $\gamma_{1} \ldots \gamma_{n}$.

${ }^{43}$ We use the same approach as Schiffer and Weder (2001), who compare small and large firms with respect to financing constraints as well as other indicators of governance. They find that small firms are more constrained. 


\section{Table 5.2: Asymmetric Financing Opportunities}

Dependent variable: Answer to the question "is financing a major obstacle to running your business?"

\begin{tabular}{|c|c|c|c|}
\hline & (1) & (2) & (3) \\
\hline $\mathrm{N}$-sector firms & $\begin{array}{c}0.175 * * * \\
(0.039)\end{array}$ & & \\
\hline Share of exports & & $\begin{array}{c}-0.003 * * * \\
(0.001)\end{array}$ & \\
\hline NL & & & $\begin{array}{c}0.265^{* * * *} \\
(0.051)\end{array}$ \\
\hline NS & & & $\begin{array}{l}0.094 * \\
(0.053)\end{array}$ \\
\hline Age & & & $\begin{array}{l}-0.000 \\
(0.001)\end{array}$ \\
\hline Government share & & & $\begin{array}{c}-0.004 * * * \\
(0.001)\end{array}$ \\
\hline
\end{tabular}

Note: This table reports regression results of ordered probit regressions, specified with a constant and with country dummies. The answer to the question "is financing a major obstacle to running your business?" is evaluated on a scale from 1 to 4 . The independent variable in regressions 1 and 3 is a dummy that is equal to one for $\mathrm{N}$ sector firms and zero otherwise. In regression 2 , it is the share of exports among $\mathrm{T}$-sector firms. In regression $3, \mathrm{NL}=$ Non tradable and large, NS $=$ Non tradable and small, the age of the firm, and the share of government participation. Standard errors are reported in parentheses; * indicates significance at the 10 percent level, ** indicates significance at the 5 percent level and $* * *$ indicates significance at the 1 percent level. 


\section{Systemic guarantees}

Despite the fact that bailout guarantees have played an important role in several explanations of crises, the evidence supporting the existence of this distortion is mainly anecdotal. Although many countries have systemic guarantees in place, it is very difficult to document their existence directly. The difficulty in pinning guarantees down is that in most cases they are implicit. To begin with, they are not limited to promises to hand out a bailout payment to lenders in case of default. In most cases they are implicit in the exchange rate regime and monetary policy rules. Since in most instances one of the objectives of policymakers is to avoid sharp drops in output, they will implement policies that are, de facto, implicit guarantees against systemic crises. ${ }^{44}$

The question arises as to how to establish the existence of implicit guarantees. We address this question by looking at the behavior of interest rate spreads. The idea is that if guarantees are present, the spread will, ceteris paribus, be insensitive to a deterioration in the average quality of loans, assuming, of course, that no crisis has yet occurred. When a crisis occurs, the quality of loans collapses and the spread skyrockets.

An ideal way to measure the evolution of the loans' quality is with the 'true' share of non-performing loans (NPLs). Unfortunately, such data in time series form does not exist for most MICs. A good proxy for an increase in NPLs is the occurrence of a lending boom in the recent past. When there is a sharp acceleration in credit, the monitoring capacity of both banks and regulators is diminished, so that there is an increase in the likelihood of granting credit to bad projects. The increase in the share of NPLs may take some time to materialize because it takes time for a given loan to become non-performing and because during the boom a lot of new loans are being granted. Nonetheless, after some time NPLs must become a problem for the banking system. This is true regardless of whether NPLs are officially recorded. To capture this idea we run the following panel regression

$$
(\rho-r)_{j, t}=\alpha_{j}+\alpha_{1} L B_{j, t-1}+\alpha_{2} D_{j, t} \cdot L B_{j, t-1}+\varepsilon_{j, t},
$$

where $(\rho-r)_{j, t}$ is the interest rate spread as defined earlier, in country $j$ at time t. $L B_{j, t-1}$ is a dummy that indicates the existence of a lending boom. It is equal to one if during the past 2 years real credit has grown by more than $10 \%$ on

\footnotetext{
${ }^{44}$ Systemic guarantees are not the same as deposit insurance schemes, which cover individual agents against idiosyncratic risk.
} 


\section{Table 5.3: Implicit Bailout Guarantees}

Dependent variable: Interest rate spread

\begin{tabular}{lcccc}
\hline \hline & \multicolumn{2}{c}{ (a) MIC 8 } & \multicolumn{2}{c}{ (b) Group of 39 } \\
\cline { 2 - 5 }$L B_{\mathrm{j}, \mathrm{t}-1}$ & $(1)$ & $(2)$ & $(3)$ & $(4)$ \\
\cline { 2 - 5 }$D_{\mathrm{j}, \mathrm{t}} * L B_{\mathrm{j}, \mathrm{t}-1}$ & $\left(0.559^{* * *}\right.$ & 1.330 & $0.723^{* *}$ & -0.188 \\
& & $(0.875)$ & $(0.348)$ & $(0.485)$ \\
$\mathrm{Adj} . \mathrm{R}^{2}$ & & $3.849^{* * *}$ & & $2.833^{* * *}$ \\
$\mathrm{~N}$ & 0.531 & $(1.131)$ & & $(1.007)$ \\
\hline \hline
\end{tabular}

Note: The table shows the estimates of the panel regression in (5.1). The lending boom dummy, $L B$, is equal to one, if the growth rate of real credit has been larger than 10 percent on average for the past two years. The crisis dummy, $D$, indicates that a twin crisis occurred in $t$ or $t+1$. The regressions are estimated with fixed effects, using a GLS estimator. Standard errors are reported in parentheses; * indicates significance at the 10 percent level, ** indicates significance at the 5 percent level and $* * *$ indicates significance at the 1 percent level.

average. $D_{j, t}$ is a dummy that indicates that twin banking and currency crises have occurred at $t$ or $t-1$.

The coefficient $\alpha_{1}$ measures the effect of an increase in NPLs on the spread in country-years in which a crisis has not occurred in either the current or the previous year. Meanwhile, the sum $\alpha_{1}+\alpha_{2}$ measures the effect of an increase in NPLs on the spread during crisis times (at $t$ or $t-1$ ). As we discussed above, in order to isolate the effect of guarantees we need to distinguish between periods in which a crisis has not occurred recently, and periods where a crisis has occurred recently. This is because systemic crises are typically preceded by lending booms and during crises the spread shoots up.

The null hypothesis that there are systemic guarantees is $H_{0}: \alpha_{1}=0$. Table 5.3 exhibits the estimates of regression (5.1). Panel (a) considers the set of 8 MICs used in the VARs, while panel (b) considers the 39 MICs. In both cases we cannot reject the null at the $10 \%$ significance level. That is, we cannot reject the presence of systemic guarantees. Interestingly, if the crisis dummy is disregarded and the spread is regressed only on the lending boom dummy, the estimated coefficient is statistically significant at the $10 \%$ level. $^{45}$

\footnotetext{
${ }^{45}$ If we were to define systemic guarantees literally as promises to hand out a bailout payment
} 


\section{Currency Mismatch and Banks Exposure to the N-sector}

Currency mismatch $(\mathrm{CM})$ exits when liabilities are denominated in foreign currency, while the income streams that must service these debts are denominated in domestic currency. CM has become an important issue in MICs because sudden real depreciations increase significantly the debt burden of a large group of agents, generating a meltdown of the banking system.

Unfortunately, there are no readily available indices of CM, so the question arises as to how best to measure this concept. First of all, CM need not be a problem that affects the aggregate economy. It is a sectorial problem that mainly affects the $\mathrm{N}$-sector. It may well be the case that there is enough foreign currency available to service the debt. However, if N-sector debtors and the banks that lend to them have $\mathrm{CM}$, then a real depreciation might generate a meltdown, unless the government can implement a redistribution from the $\mathrm{T}$ to the $\mathrm{N}$-sector on short notice. Clearly, these fiscal transfers are not feasible.

Since in MICs banks are heavily exposed to the N-sector, we can get a more precise indicator of CM by looking at the balance sheet of the banking system. Table 5.4 shows that, on average, only about a third of bank lending goes to firms that can potentially be classified as belonging to the tradeable sector. This indicates that the banking system is strongly exposed to the N-sector. ${ }^{46}$

Since banks are strongly exposed to the $\mathrm{N}$-sector we cannot determine the degree of $\mathrm{CM}$ by simply comparing the liabilities and the assets of the banking system. A bank can have $20 \%$ of its liabilities in dollars and $20 \%$ of its assets denominated in dollars. However, if all the loans are granted to the N-sector, there is a de facto CM because there is insolvency risk. It may be even more misleading just to compare the denomination of deposits and loans, as these are

to lenders in case of default, we could investigate the proportion of crises that have triggered this type of bailouts, and then impose rational expectations to infer the ex-ante implicit guarantee. Bordo and Schwarz (2001) and Jeanne and Zettelmeyer (2000) find evidence of ex-post bailouts during the last two decades and the early banking crises of the 20th century.

${ }^{46} \mathrm{In}$ order to bias the results against the hypothesis that banks are heavily exposed to the $\mathrm{N}$-sector, we assume that all firms in sectors that are commonly considered tradable are indeed tradable. Thus, we group manufacturing, mining, agriculture, forestry, and primary production as tradables, while construction, services, electricity-gas-water are considered nontradables. Note that the fraction of bank lending that goes to consumption or housing credit is not covered by foreign currency income and thus also counts as non-tradable. In most countries, the figures would be even higher if these items where included (consumption and housing credit are only available for Hungary, Mexico and Thailand). 
Table 5.4: Bank Lending by Sector

\begin{tabular}{lcr}
\hline \hline & \multicolumn{2}{c}{ Assets } \\
\cline { 2 - 3 } & $\begin{array}{l}\text { Loans to Non- } \\
\text { tradables }\end{array}$ & $\begin{array}{l}\text { Loans to } \\
\text { Tradables }\end{array}$ \\
\cline { 2 - 3 } Argentina (95) & $67.1^{3}$ & 32.9 \\
Chile (85) & 60.1 & 39.9 \\
Korea (97) & $74.8^{5}$ & 25.1 \\
Mexico (95) & 66.0 & 33.9 \\
Peru (96) & 59.2 & 40.8 \\
Thailand (97) & 66.5 & 34.5 \\
Turkey (93) & $34.0^{4}$ & 66.0 \\
\hline \hline
\end{tabular}

Sources: See appendix.

Notes: 1) N-Sectors: Construction, Real Estate Business, Infrastructure, Services, Personal Consumption, Commerce, Wholesale and Retail, Housing, Electricity-Gas-Water, Restaurants, Hotels, Transportation, Small firms. 2) TSectors: Mining, Quarrying, Industry, Agriculture, Forestry; Industrial Sector, Foreign entities, Primary Production, Imports, trade, Large, Other 3) including consumption or Housing credit. 4) only consumption credit is $\mathrm{N}$ 5) $\mathrm{N}$ is proxied by small, $\mathrm{T}$ is proxied by large firms.

only a subset, and a small subset at that, of the total balance sheet. ${ }^{47}$

Our index of CM compares the share of foreign currency liabilities of the banking system to the share of loans that are covered by export income. We compute the latter ratio by multiplying the share of bank lending that goes to the T-sector by the share of T-sector output that is actually exported. Column (c) in Table 5.5 shows that exporting firms sell the majority of their output in the domestic market. Thus, they too must earmark a large share of domestic currency revenue for servicing foreign currency debt.

Our index of CM is reported in column (e) of Table 5.5. The estimates range from 2.97 for Korea in 1997 to 4.34 for Mexico in $1995 .{ }^{48}$ To see that CM is mostly a sectorial, not an aggregate, problem compare Table 5.5 with Table 5.6.

\footnotetext{
${ }^{47}$ For instance, foreign currency deposits in Thailand account for less than $10 \%$ of the total foreign external liabilities of the banking system.

${ }^{48}$ Our estimates of $\mathrm{CM}$ are conservative. More realistic/accurate estimates would take into account that the amount of foreign currency revenue that is available to service debt is less than total foreign currency income. Some of the foreign currency income is required to pay off the factors of production.
} 
Table 5.5: Share of foreign currency liabilities covered by income from exports

\begin{tabular}{lccccc}
\hline \hline & Liabilities & Assets & \multicolumn{2}{c}{$\begin{array}{c}\text { Foreign currency } \\
\text { coverage of assets }\end{array}$} & $\begin{array}{c}\text { Currency } \\
\text { Mismatch }\end{array}$ \\
\cline { 2 - 5 } & $\begin{array}{c}\text { (a) } \\
\text { \% of foreign } \\
\text { currency } \\
\text { liabilities }\end{array}$ & $\begin{array}{c}\text { (b) } \\
\text { Loans to } \\
\text { Tradables }\end{array}$ & $\begin{array}{c}\text { (c) } \\
\text { Export/ } \\
\text { output }\end{array}$ & $\begin{array}{c}(\mathrm{d}) \\
(\mathrm{b}) *(\mathrm{c})\end{array}$ & $\begin{array}{c}(\mathrm{e}) \\
(\mathrm{a}) /(\mathrm{d}), \\
\left.\text { (lower bound }{ }^{3}\right)\end{array}$ \\
\cline { 2 - 6 } Argentina (95) & 35.0 & 32.9 & 0.30 & 9.8 & 3.57 \\
Chile (83) & 46.7 & $39.9^{1}$ & 0.28 & 11.2 & 4.17 \\
Korea (97) & $17.9^{2}$ & 25.1 & 0.34 & 8.53 & 2.97 \\
Mexico (95) & 33.4 & 33.9 & 0.23 & 7.7 & 4.34 \\
Peru (96) & 73.0 & 59.2 & 0.34 & 20.1 & 3.62 \\
Thailand (97) & 22.3 & 34.5 & 0.17 & 5.8 & 3.85 \\
Turkey (93) & 47.0 & 66.0 & 0.24 & 15.84 & 2.97 \\
\hline \hline
\end{tabular}

Sources: see appendix.

Note. 1) Data on loans in Chile are from 1985 2) Foreign liabilities data in Korea is from 1993 - thus currency mismatch in 97 must have been much larger. 3) The results are biased against finding our hypothesis of currency mismatch in several important ways 1) Off balance sheet items are not included, which are primarily in foreign currency. 2) Due to legislation Banks tend to underreport their foreign currency holdings as a share of liabilities (see Kamin et. al 2001) 3) We assume that all revenues from exports can be used to service the debt. All firms in potentially tradable sectors are assumed to indeed be tradable. 
Table 5.6: Aggregate indicators of currency mismatch

\begin{tabular}{|c|c|c|}
\hline & $\begin{array}{l}\text { Foreign debt Service/ } \\
\text { Exports }\end{array}$ & Foreign debt/ Exports \\
\hline Argentina & 0.37 & 4.73 \\
\hline Chile & 0.26 & 2.13 \\
\hline Korea & 0.09 & 0.76 \\
\hline Mexico & 0.36 & 2.30 \\
\hline Peru & 0.25 & 5.77 \\
\hline Thailand & 0.18 & 1.47 \\
\hline Turkey & 0.56 & 3.60 \\
\hline
\end{tabular}

Source: World Bank Development indicators (year: 1994)

Notice that the foreign debt service-to-exports ratio is low in countries with a high CM index. A banking system where only 15-30\% of dollars loans are covered by exports are certainly subject to substantial real exchange rate risk. This is true even though the aggregate measures of Table 5.6 do not indicate CM. ${ }^{49}$

\section{Extensions}

Here, we briefly analyze how the economy responds to monetary shocks under alternative exchange rate regimes and delve into the determinants of the spread $\rho_{t}-r$ in MICs. A simple way to introduce monetary shocks is to add credit from the central bank to the fiscal authority $\left(D C_{t}\right)$ to money supply equation (3.7). The money market equilibrium $\left(M_{t}^{s}=M_{t}^{d}\right)$ then becomes

$$
\begin{aligned}
R_{t}+\frac{D C_{t}}{e_{t}} & =\frac{p_{t}^{n} q_{t}^{n}}{e_{t}} \\
& =p_{t} q_{t}^{n}=d_{t}+\mu\left(g_{t}\right) w_{t}
\end{aligned}
$$

The second equality follows from the definition of the real exchange rate (3.1), while the third follows from the the equilibrium value of N-output $p_{t} q_{t}^{n}$ characterized in Proposition 3.2.

\footnotetext{
${ }^{49} \mathrm{~A}$ high foreign debt service-to-exports ratio signals a CM problem. However, just because this aggregate measure may be low, one cannot infer that there is no CM.
} 
Consider an expansionary shock to $D C_{t}$. The first point to notice is that the equilibrium demand for money (i.e., $d_{t}+\mu\left(g_{t}\right) w_{t}$ ) remains unchanged. This is because in the RSE of Proposition 3.2 the $D C_{t}$ shock affects neither the investment multiplier $\left(\mu_{t}\right)$ nor the net worth of N-firms $\left(w_{t}\right)$, as can be seen in (3.13) and (3.17).

It follows that under fixed exchange rates there is a decline in reserves $\left(e_{t} \Delta R_{t}=\right.$ $\left.\Delta D C_{t}\right)$, while under flexible exchange rates there is a nominal devaluation $\left(\Delta \% e_{t}=\right.$ $\left.\Delta \% D C_{t}\right)$. Since $e_{t}$ appears in the right hand side of (6.1), which must remain unchanged in an RSE, it is necessary that $\Delta \%\left(p_{t}^{n} q_{t}^{n}\right)=\Delta \% e_{t}$. This condition is consistent with either non-tradables inflation $\left(\Delta p_{t}^{n}\right)$ or an increase in N-output $\left(\Delta q_{t}^{n}\right)$. The particular outcome depends on the character of the nominal rigidity. This is an important issue, but not the focus of our paper..$^{50}$

A monetary shock does not affect $b_{t}, p_{t} q_{t}^{n}$ or $q_{t}^{t r}$ because it affects neither the lending rate at which bank-dependent $\mathrm{N}$-sector agents finance themselves $\left(\rho_{t}\right)$, nor the cost of external funds faced by T-firms $(r)$, who can finance themselves in international financial markets. ${ }^{51}$

The fact that shocks to $D C_{t}$ do not directly affect variables such as bank credit or investment, does not mean that monetary policy has no effects in MICs. It does affect the economy through its impact on the expected generosity of systemic guarantees $\left(g_{t}\right)$. Monetary policy announcements may signal the willingness of the government to grant bailouts. Of course, it is ultimately the fiscal stance what determines the ability to finance such bailouts.

\section{Related Literature}

There is a vast literature on the effects of monetary shocks on output. Our work is closely related to the subset of this literature devoted to the credit channel. Investigations into whether monetary policy affects output through a credit channel, in addition to the traditional money channel, have focused on the link between interest rate spreads and future movements in output. This link has been established in US data by Stock and Watson (1989), and Friedman and Kuttner (1992). Bernanke, Gertler and Gilchist (2000) show that this link is consistent

\footnotetext{
${ }^{50}$ See, for instance, Gali and Monacelli (2002) for an analysis of monetary policy in a small open economy with price rigidities.

${ }^{51}$ Our results are related to the equivalence of exchange rate regimes established by Helpman (1981).
} 
with the existence of a financial accelerator and that the spread is an indicator of the stance of monetary policy. However, Bernanke (1990) finds that the strength of this link has been declining over time, and Friedman and Kuttner (1998) point out that the spread failed to predict the 1990 recession. In related work, Kashyap et. al. (1993) consider the mix of loans and commercial paper to investigate the existence of the credit channel.

The VARs we derive and estimate are similar to the ones alluded to above as they link a spread with credit and output. An attractive feature of our empirical exercise is that the impulse responses we exhibit are structurally identified by the restrictions implied by the equilibrium of our model.

In order to uncover the propagation mechanism that underlies the credit channel, a series of papers look at the asymmetric behavior of small and large firms. Gertler and Gilchrist (1994) find that, in the manufacturing sector, small firms react more strongly to monetary contractions than large firms. This evidence is associated with the fact that large firms are less bank-dependent and make greater use of equity and bonds markets. Ramey (1993) finds that the ratio of credit to small and large firms has some effect on aggregate output. Kashyap and Stein (2000) find that, after a contractionary monetary shock, lending of small banks declines more strongly than that of large banks. They argue that -as with small firms- small banks have more difficulty in accessing uninsured sources of funds.

The asymmetry between small and large agents is also key in MICs. However, as we document in this paper, in MICs this asymmetry also distinguishes the $\mathrm{N}$ and T sectors: small firms are mainly in the $\mathrm{N}$ sector, while large firms are mainly in the T-sector. This asymmetry is the key to our finding that the N-to-T output ratio declines significantly in response to an increase in the spread in the second group of VARs we run. Furthermore, this asymmetry allows us to rationalize the important role played by real exchange rate fluctuations in MICs.

There is a growing number of country studies that try to uncover the importance of credit market imperfections in MICs. See for instance Aizenmann et. al. (1998) for Argentina, Ber et. al. (2001) for Israel and Gelos et. al. (2002) for Mexico.

The model in this paper is closely related to Schneider and Tornell (2000). In order to explain low frequency boom-bust cycles and self fulfilling twin crises, they characterize the explosive paths of an economy with endogenous uncertainty. In contrast, we are interested in deriving structural VARs that apply to high frequency fluctuations, and not just to crises. Thus, we consider an economy hit by exogenous shocks and characterize the equilibrium fluctuations around a steady 
state. Other papers that analyze the implications of credit market imperfections in MICs include Aghion, Bacchetta and Banerjee (2000), Burnside, Eichenbaum and Rebelo (2000), Caballero and Krishnamurthy (1999), Cespedes, Chang and Velasco (2001), Corsetti, Pesenti and Roubini (1999), Dekle and Kletzer (2001), Mckinnon and Pill (1998) and Tirole (2002).

\section{Conclusions}

In the past, inflation and fiscal deficits were the main danger facing middle income countries (MICs). But in recent years, the biggest hazards have instead been lending booms and asset-price inflation -or its cousin, real exchange rate appreciation. Credit market imperfections are at the heart of these phenomena, with sectorial asymmetries between $\mathrm{N}$ - and T-sectors, playing a key role in the amplification of shocks.

In this paper we have presented a model that helps us think about these new hazards. The model captures the credit market imperfections prevalent in MICs, and leads to a structural estimation framework suitable to analyze economic fluctuations in a world of liberalized financial flows, but with asymmetric financing opportunities across sectors.

The evidence presented here shows that, in spite of the many ways MICs are distinct from one another, they have in common the patterns of several macroeconomic variables. In particular, an increase in the spread between domestic and international interest rates has a strong effect on GDP and an even stronger effect on domestic credit. In addition, movements in credit are strongly correlated with those of investment, the real exchange rate, and the ratio of nontradables $(\mathrm{N})$ to tradables (T) output.

That the relationship between these variables should be the same, irrespective of differences in other country characteristics, suggests a common shock propagation mechanism. Our findings indicate that the literature on the financial accelerator developed to explain macroeconomic patterns in high income countries is extremely relevant to understanding economic fluctuations in MICs. However, MICs share common features that distinguish them from high income countries. For the latter, access to external funds tends to depend on size. For MICs, the size distinction is also a distinction between the $\mathrm{N}$ and $\mathrm{T}$ sectors, and thus real exchange rate fluctuations play a key role in the amplifying mechanism. Another important difference is that monetary policy is far less effective at altering the interest rates that matter to investment in MICs. 
At the heart of the MIC credit channel is the interaction of two credit market imperfections: a deep asymmetry in financing opportunities across $\mathrm{N}$ and $\mathrm{T}$ sectors and government guarantees that cover lenders against systemic default. In MICs T-sector firms have access to international capital markets, while most N-firms are bank-dependent and are financially constrained. Systemic guarantees generate incentives for borrowers to take on insolvency risk by denominating debt in foreign currency. This currency mismatch makes movements in the real exchange rate - the relative price between $\mathrm{N}$ and $\mathrm{T}$ goods- the driving element in the amplification of shocks. Any shock that increases the cost of domestic funds depresses investment demand and generates a real depreciation, which, in turn, further depresses net worth and investment, leading to a greater real depreciation, and so on. This is the balance sheet effect that is responsible for the credit channel's strength in MICs.

We have examined the balance sheet effect from several different angles. We presented stylized facts common to MICs that are suggestive of the balance sheet effect. We have presented a model that reconciles these facts and leads to a well specified estimation framework. The resulting VARs allowed us to structurally identify shocks to credit market conditions and trace their effects on economic fluctuations. The effects we find in the data are consistent with those generated by a simulation of the model. Furthermore, we show that the model's key assumptions are consistent with evidence gleaned from both firm level and aggregate data. It is the combination of these different approaches that gives us confidence in the robustness of our conclusions. Of course, we are not ruling out alternative mechanisms, but are not aware of any that is capable of explaining simultaneously all of the regularities we have documented.

An implication of our work is that sectorial indicators may be as crucial as aggregate ones for understanding MIC performance. Currency mismatch is not a problem because it jeopardizes a country's ability to repay debt in the event of a real depreciation. Rather, it is a problem because, in the absence of fiscal transfers from T-sector firms, it imperils N-sector borrowers and their creditors. Real exchange rate fluctuations may not primarily reflect changes in the relative price of domestic and foreign tradable goods, but instead sectorial imbalances. Robust increases in aggregate output driven by T-firms may hide a languishing domestic sector, raising the prospect of future bottlenecks choking off growth.

It follows that in a world of financial liberalization and of asymmetries in financing opportunities across $\mathrm{N}$ - and T-sectors, low inflation is not a guarantee of economic stability. If the balance sheet effect is at work, stabilization policies 
should concentrate not only on inflation and the output gap, but also on indicators such as credit growth and asymmetries in sectorial responses.

We have focused on variables such as credit and investment, the behavior of which is independent of the exchange rate regime and the degree of nominal rigidity. This has allowed our empirical analysis to uncover patterns that are common across MICs. There are important variables, such as inflation and unemployment, which we have not focused on. We plan to do so in future work.

\section{References}

[1] Agenor, P., J. Aizenman and A. Hoffmaister, (1998), "Contagion, Bank Lending Spreads and Output Fluctuations," NBER working paper 6850.

[2] Aghion, P., P. Bachetta, and A. Banerjee (2000), "Capital Markets and the Instability of Open Economies," mimeo, Study Center Gerzensee.

[3] Bekaert, G. and H. Campbell (2001), "Economic Growth and Financial Liberalization," mimeo.

[4] Ber, H., A. Blass and O. Yosha (2002), "Monetary Policy in an Open Economy: The Differential Impact of Exporting and Non-Exporting Firms," mimeo, Tel Aviv University.

[5] Bernanke, B. (1990), "On the Predictive Power of Interest Rates and Interest Rate Spreads," New England Economic Review, pp. 51-68.

[6] Bernanke, B., M. Gertler and S. Gilchrist (2000), "The Financial Accelerator in a Quantitative Business Cycle Framework" in Handook of Macroeconomics, Taylor and Woodford eds.

[7] Betts, Caroline M. and Timothy J. Kehoe (2002), "Real Exchange Rate Movements and the Relative Price of Nontraded Goods," Federal Reserve Bank of Minneapolis, Staff Report.

[8] Bordo, M. and A. Schwartz (2001) "Measuring Real Economic Effects of Bailouts" NBER working paper 7701.

[9] Burnside, C., M. Eichenbaum and S. Rebelo (2001), "Prospective Deficits and the Asian Currency Crisis," Journal of Political Economy, 109(6), 1155-97. 
[10] Caballero, R. and A. Krishnamurthy (2001), "International and Domestic Collateral Constraints in a Model of Emerging Market Crises," Journal of Monetary Economics, 48 (3), 513-48.

[11] Cespedes, L., R. Chang and A. Velasco (2001), "Balance Sheets and Exchange Rate Policies," NBER working paper 7840.

[12] Cheung, Y. W. and K. S. Lai, (1993), Finite Sample Sizes of Johansen's Likelihood Ratio Tests for Cointegration, Oxford Bulletin of Economics and Statistics 55, pp. 313-28.

[13] Corsetti, G., P. Pesenti and N. Roubini (1999), "Paper Tigers: A Model of the Asian Crisis" European Economic Review 43(7), 1211-36.

[14] Dekle, R. and K. Kletzer (2001), "Domestic Bank Regulation and Financial Crisis: Theory and Empirical Evidence From East Asia" NBER working paper 8322.

[15] Engle, C. (1999), "Accounting for U.S. Real Exchange Rates," Journal of Political Economy, 107(3), 507-38.

[16] Friedman, B. and K. Kuttner (1992), "Money, Income, Prices, and Interest Rates," American Economic Review, Vol. 82, pp. 472-492.

[17] Friedman, B and K. Kuttner (1998), "Indicator Properties of the PaperBill Spread: Lessons From Recent Experience," Review of Economics and Statistics, pp. 34-44.

[18] Gali, J. and T. Monacelli (2002), "Monetary Policy and Exchange Rate Volatility in a Small Open Economy" NBER working paper 8905.

[19] Gelos, G. and A. Werner (2002), "Financial liberalization, Credit Constraints, and Collateral: Investment in the Mexican Manufacturing Sector," Journal of Development Economics, 67(1): 1-27.

[20] Gertler, Mark and Simon Gilchrist (1994), "Monetary Policy, Business Cycles, and the Behavior of Small Manufacturing Firms," Quarterly Journal of Economics; 109, pp. 309-40.

[21] Helpman, E. (1981), "An Exploration in the Theory of Exchange Rate Regimes," Journal of Political Economy, 89 (5), 865-90. 
[22] Jeanne, O. and J. Zettelmeyer (2001), "International Bailouts, Moral Hazard and Coditionality," Economic Policy, October.

[23] Kashyap, A., J. Stein and D. Wilcox (1993), "Monetary Policy and Credit Conditions: Evidence From the Composition of External Finance," American Economic Review 83, June 1993, 78-98.

[24] Kashyap, A., and J. Stein (2000), "What Do a Million Observations on Banks Say About the Transmission of Monetary Policy?" American Economic Review; 90(3), pp. 407-28.

[25] McKinnon, R. and H. Pill (1997), "Credible Economic Liberalizations and Overborrowing," American Economic Review 87(2), 189-93.

[26] Ramey, V. (1993), "How Important is the Credit Channel in Monetary Transmission?" Carnegie-Rochester Conference Series on Public Policy, 39, 1-45.

[27] Schiffer, M. and B. Weder (2001), "Firm Size and the Business Environment: Worldwide Survey Results," IFC discussion paper 43.

[28] Sims, C. (1980), "Macroeconomics and Reality," Econometrica, 48(1), pp. $1-48$.

[29] Schneider, M. and A. Tornell (2000), "Balance Sheet Effects, Bailout Guarantees and Financial Crises," NBER working paper 8060.

[30] Stock, J. and M. Watson (1989), "Interpreting the Evidence on MoneyIncome Causality", Journal of Econometrics, 40(1), pp. 161-81.

[31] Tirole, J. (2002), "Inefficient foreign borrowing, a dual - and common - agency persective", mimeo.

[32] Tornell, A. and F. Westermann (2002), "Boom-Bust Cycles: Facts and Explanation", NBER working paper 9219. 


\section{Appendix}

\section{Proof of Proposition 3.2}

We determine first when a bad shock at $t+1$ will lead to insolvency. Suppose that incumbent managers enter $t+1$ with a supply of nontradables $q_{t+1}$ and a debt burden of $\left(1+\rho_{t}\right) b_{t}$ dollars. Thus, dollar profits are $\pi_{t+1}=p_{t+1} q_{t+1}-\left(1+\rho_{t}\right) b_{t}$. It follows that if $p_{t+1}$ is below a cutoff price $p_{t+1}^{c}=\frac{\left(1+\rho_{t}\right) b_{t}}{q_{t+1}}$, all firms go bust and $w_{t+1}$ equals $\underline{w}_{t+1}$. Since in an RSE the debt burden is $\left(1+\rho_{t}\right) b_{t}=\alpha^{-1} h \mu_{t} w_{t}$, we have that $\underline{p}_{t+1}<p_{t+1}^{c}$ if and only if the aid payment satisfies (3.19). Using (3.16) and $p_{t+1} I_{t+1}=\mu_{t+1} w_{t+1}$ we can see that (3.19) is equivalent to $\frac{\theta \underline{p}_{t+1}}{p_{t}}<\frac{h}{\alpha}$ in (3.10).

Next, we determine the conditions under which the production of N-goods has a positive NPV: $\alpha \frac{\theta \bar{p}_{t+1}}{p_{t}} \geq 1+r$. Replacing (3.9) and (3.13) in (3.16), it follows that

$$
\alpha \frac{\theta \bar{p}_{t+1}}{p_{t}}=\alpha \frac{d+\mu_{t+1} w_{t+1}}{\mu_{t} w_{t}} \geq 1+r
$$

Some algebra reveals that $w_{t}>0$ and the sequence $\left\{w_{t+1} / w_{t}\right\}$ generated by net worth equation (3.17) satisfies (8.1) for all $t$ and all guarantees' sequences $\left\{g_{t}\right\}$ if and only if (3.20) holds.

In order to establish the existence of a stable RSE we just need to verify that (3.20), $h<\alpha[1+r]$ and $\eta_{t}<1$ for all $g_{t}$ are consistent with each other. The second condition is necessary for borrowing constraints to exist, while the third one is necessary for stability. Since $\bar{\eta}=\frac{1-c}{1-\alpha^{-1} h[1+r]^{-1}}$ and $0<c<1$, we have that $\alpha^{-1} h<[1+r]$ implies that $\bar{\eta}$ must be positive. We can then ensure that (3.20) holds by setting $\alpha^{-1} h$ low and $c$ high. Lastly, $\eta_{t}<1$ for all $g_{t}$ if and only if $\bar{\eta}<1$. This condition is implied by (3.20).

\section{Data Sources and Definitions}

1. Panel regression. Source: World Bank Development Indicators (WBDI), IFS (IMF) and OECD Statistical Compendium.

Criteria for country selection: We consider countries: a) that have a stock market and the value of the stocks traded as a share of GDP is larger than 1\%,b) that have a population of more than 1 million people, c) that have a per capita income of more than $\$ 1000$ but less than $\$ 18000$ and d)that are not engaged in war or civil war (Iran, Iraq, Yugoslavia and Lebanon). In addition, we consider Finland and Sweden. In total we have 39 countries. The sample covers 20 years, from 1980 to 1999. The panel is unbalanced, as not all series cover the full sample or are available for all countries. 
Variables included in the regression: Real credit growth: IMF, International financial Statistics, CD-ROM. Claims on private sector by deposit money banks (Lines 22d..ZF), divided by CPI (Lines 64..ZF); N/T: Services: World Bank Development indicators (Code: NV.SRV.TETC.KN), Manufacturing: World Bank Development indicators (Code: NV.IND.MANF.KN), Construction: OECD Statistical Compendium, Main indicators of industrial activity and individual central banks. See Tornell and Westermann (2002) for selection criteria for N and T- Sectors; Interest rate spread: World Bank Development indicators (Code: FR.INR.LNDP); Real interest rate: World Bank Development indicators (Code: FR.INR.RINR); Gross domestic fixed investment: World Bank Development indicators (Code: NE.GDI.FTOT.KN); Private Consumption: World Bank Development indicators (Code: NE.CON.PRVT.KN)

2. VARs. Source: International Financial Statistics (IFS) and country sources. Variables included in the VARs: PPI: IFS, line 63..ZF; CPI: IFS, Line 64..ZF; Nominal GDP: IFS, line 99B..ZF; Credit: Deposit Money Banks, claims on the private sector. IFS, line 22D..ZF; The real exchange rate is computed as the ratio of PPI/CPI; Nominal GDP and Credit are deflated using the PPI index; T-Sector is proxied by Manufacturing: International Financial Statistics; N Sector is proxied by Construction: the respective national source: Argentina: Dirección Nacional de Cuentas Nacionales; Chile: Banco Central de Chile; Korea: Bank of Korea; Mexico: Bank of Mexico; Peru: Página Web BCR; Thailand: Bank of Thailand, Economic Data and Accounting System Office, NESDB; Turkey: Central Bank of the Republic of Turkey; Japan: Bank of Japan; Germany: Statistisches Bundesamt; USA: Federal Reserve Bank of St. Luis; Sectorial data output data are available from authors upon request.

3. Probit regressions. Source: World Business Economic Survey (WBES).

Variables included in the regressions: label var gcf "General constraintfinancing" $1=$ no obstacle $4=$ major obstacle; label var exp_yn "Exports" $1=y e s$, $2=$ no; label var exp_pct " $\%$ of output exported"; label var yr_estb "year established"; label var gvt_pct "Percent government ownership."

4. Currency Mismatch: Sources: Sources: Bank of Argentina, Bank of Brazil, Bank of Korea, Bank of Peru, Bank of Turkey, BANXICO, Dirección General de Investigación Económica. Indicadores Económicos, May 1996 and 2001. Dziobek, Claudia, J. Kim Hobbs and David Marston, 2000, "Toward a Framework for Systemic Liquidity Policy," IMF Working Paper 00/34 (Washington: International Monetary Fund). Takatoshi Ito and Luiz A. Pereira da Silva: "The Credit Crunch in Thailand during the 1997-98 Crisis: Theoretical and operational issues with 
the JEXIM survey". Steven Kamin, Philip Turner and Jozef Van 't dack*, "The transmission mechanism of monetary policy in emerging market economies: an overview", mimeo, BIS conference, OECD Bank Profitaility statisitics. 